\title{
Applied Participatory Priority Setting in International Agricultural Research: Making Trade-offs Transparent and Explicit
}

\author{
T. G. Kelley, J. G. Ryan \\ International Crops Research Institute for the Semi-Arid Tropics (ICRISAT), \\ Patancheru, Andhra Pradesh 502-324, India
}

$\&$

B. K. Patel

Rockefeller Foundation, SAASP, P.O. Box 30721, Lilongwe 3, Malawi

(Received 9 March 1994; accepted 15 August 1994)

\section{$A B S T R A C T$}

This paper describes an ex-ante multi-objective framework (economic effciency, equity, internationality and sustainability) for assessing research priorities at an international agricultural research center. With its supplyside methodological orientation it complements the Technical Advisory Committee/Consultative Group on International Agricultural Research demand-side analysis and thus represents a step forward in formulating research agendas. The distinct advantage of the framework described here is that at a time of intense competition for scarce funds, it makes explicit the benefits that would flow from additional investrments to an institule as well as the opportunity costs corresponding to reductions. This kind of information is useful for the TAC and the CGIAR Secretariat in making decisions about allocating scarce research resources across CGIAR centers.

The methodology used in setting research priorities for ICRISAT'S (International Crops Research for the Semi-Arid Tropics) $199498 \mathrm{Med}$ ium Term Plan provides clear criteria for establishing choices among competing research activities, is analytically rigorous, draws on scientists, empirical and intuitive knowledge base, and is transparent and interactive. Research themes identified are impact-oriented, projecting clear milestones against which progress can be measured and evaluated ex-post. Thus, assumptions about prospective yield increases, research lags, probabilities 
of success, and adoption lags and ceilings can be tested against actual delivery of a new research-induced technology. This forms an integral part of the research evaluation process and facilitates revising priorities in the light of such experiences.

\section{INTRODUCTION}

One of the major problems facing not-for-profit agricultural research in this decade is the lack of funds. This 'new poverty' adds urgency to the optimum allocation of scarce development research resources among organizations, geographic locations, commodities and projects. It also increases the need to consider the implications of alternative choices for such long-standing concerns as sustainablity and preferential outcomes for the poor.

Gryseels et al. (1992) have presented a prior setting framework for use by the Technical Advisory Committee (TAC) Secretariat in allocating scarce resources among regions, commodities and activities within the Consultative Group on International Agricultural Research (CGIAR) system. Their spreadsheet scoring model approach, while commendable in many respects, has several shortcomings (Gryseels et al., 1992, p. 69; ICRISAT, 1992a; Cummings, 1992). In particular, McCalla and Ryan (1992) have highlighted the need for incorporating a supply-side analysis. Instead of assuming all institutes and programs to be equal suppliers of needed research products, this approach would allow decision makers an ex-ante assessment of specific research impact. An attempt at impactoriented priority-setting at one of the CGIAR institutes is presented in this paper.

The TAC model component closest to supply-side factors is the baseline indicator 'value of production', a proxy for expected economic benefit from research. As with other variants of the 'congruence method', priorities are determined in a manner consistent with the current relative importance of the given commodity - as measured by its share of the total value of production in a region - although in the TAC model case, priorities are suitably modified to take account of conditioning factors such as poverty, sustainability issues, and strength and commitment of the national agricultural research systems (NARS). ${ }^{1}$ The congruence-based approach implicitly assumes the potential gain per research dollar to be in proportion to that commodity's value of production, i.e. research opportunities are considered equal. The probability of research resulting in 
adoptable technology, the adoption level and size of production gain are assumed to be equal across all commodities (McCalla \& Ryan, 1992). In general, the focus on demand issues to the neglect of the supply side of the research process can lead to unrealistic assessments of potential impact (Evenson, 1992). Another weakness of the Gryseels et al. (1992) framework is its failure to consider expected impact and delivery potential of proposed research by different suppliers.

The International Crops Research Institute for the Semi-Arid Tropics (ICRISAT) developed a methodological framework for setting research priorities with a supply-side orientation. It was used in shaping its 1994-98 Medium-Term Plan (MTP); complete with specific research themes, and using an 'eclcctic' approach of methods and data collection. These research themes are impact-oriented, projecting clear milestones against which progress can be measured and evaluated.

\section{PROBLEM AND ANALYTICAL APPROACH}

Most organizations operate under mission statements or broad strategies which have to be translated into clear priorities and goals. At ICRISAT, the problem was one of prioritizing among numerous competing research possibilities to make optimum use of scarce research funds against the background of a strategic plan (ICRISAT, 1991).

Basic to an attempt at the 'supply side' of research are at least three factors which critically affect the size and timing of likely benefits from research (Fox, 1987). The first relates to the size, quality and experience of scientific staff engaged in the research. The second relates to the nature of the research problem itself and the inherent difficulty in achieving a biological (or policy) breakthrough. Finally, even when innovations do occur, there is the question of adoption, adoption lags, and ceiling levels of adoption - aspects highly dependent on factors like extension effort, general infrastructure development, and the role of private enterprise.

To ensure a rigorous decision-making process along these lines, an interactive yet focused system is needed which combines, as Gryseels et al. (1992) stipulate, informed qualitative judgement and quantitative analysis. In this case, a Working Group of scientists from across commodities, disciplines, programs and locations was constituted to coordinate activities, exchange information and generate ideas. This group helped develop the methodology and agreed-upon procedures for prioritizing research themes. From the outset, four principles guided the research planning process:

- The methodology adopted should provide clear criteria for establishing choices between competing research activities; 
- the methodology should be analytically rigorous, i.e. offer a consistent method for prioritizing;

- the research plan should be based on empirical and intuitive judgements from a knowledge base within ICRISAT and NARS;

- the process should be transparent and interactive with open presentations and discussions among all scientists in the organization.

These resulted in four major elements which characterized the process:

(1) The choice of four selection criteria which reflected the mandate of the CGIAR and ICRISAT: economic efficiency, equity, internationality, sustainability;

(2) an overall score (composite index) for each potential research theme;

(3) a formalized database of primary and secondary data;

(4) an institute-wide effort with multidisciplinary spillovers.

These are discussed in the following four sections.

\section{Clear criteria for establishing choices}

A fundamental step in any planning process is selection of criteria and associated measures against which achievements can be assessed. There must be consistency between the stated mandate and objectives of the institute and the criteria selected for measuring prospective impact or performance. In this case, the CGIAR mission statement reads:

'Through international research and related activities, and in partnership with national research systems, to contribute to sustainable improvements in the productivity of agriculture, forestry and fisheries in developing countries in ways that enhance nutrition and well-being, especially of low-income people' (TAC Secretariat, 1992: p. 10).

The ultimate objective is improving the nutrition and economic wellbeing of low-income producers and consumers, many of them women, located in the rain-fed semi-arid tropics and other resource-poor regions growing ICRISAT mandate crops. As the target beneficiaries are the poor, criteria for assessing priorities should reflect this overriding concern for them.

Translating such general objectives into clear and consistent choice criteria is not always straightforward. Reaching agreement on a set of criteria and their relative weights may not be possible initially. In this case, efficiency, equity, food security, interriationality, strength of NARS, 
stability, sustainability and comparative advantage were all considered potentially relevant criteria. Ultimately, however, four choice criteria were selected: economic efficiency, equity, internationality and sustainability; a decision influenced in some measure by the previously mentioned TAC strategies and priorities paper and deliberations by senior ICRISAT management. Nevertheless, data on all possible criteria under consideration were collected and assembled in the initial stages, followed by development of quantitative measures to adequately reflect those criteria.

\section{Analytical rigor}

The principle of analytical rigor is driven by the demand for a more systematic priority-setting mechanism which derives from both managers and scientists: managers who are under pressure from donors to make more efficient use of scarce funds, and scientists who see their research programs threatened. Increasingly, decisions based solely on individual intuitive (versus informed) judgement are viewed as unacceptable. While good judgement of senior managers cannot be replaced, analytical rigor, properly qualified by assumptions, introduces greater objectivity. Moving away from allocating funds on the basis of historical precedent and individual preference, each research activity should compete on its own merits. This necessitates the development of a method for quantifying the selected criteria for evaluating each potential research theme.

A vast amount of literature deals with methodologies for measuring the potential impact of agricultural research. ${ }^{2}$ The primary quantitative techniques used in ex-ante analysis of research priorities are scoring, simulation, mathematical programming, precedence, congruence and cost-benefit analysis. Perhaps the most widely used has been cost-benefit analysis, and more specifically, the economic surplus approaches to estimate benefits. In this paper an 'eclectic approach' is presented: a scoring model employing a weighted, additive composite index is developed to calculate an overall score for each proposed research activity or 'theme'. Subsequently, an ordinal ranking of themes and their cumulative costs emerges which defines research priorities, based as they are on a multiimpact measure of economic efficiency, equity, internationality and sustainability. Depending on the budget available, an optimum research portfolio can then be defined.

To measure economic efficiency, the expected net benefit-cost ratio was estimated using a simplified version of the producer-consumer surplus approach, i.e. estimating gross welfare benefits. Equity was measured in terms of the number of poor and the extent of female illiteracy (see the discussion in the later section on gender) in the regions where impact is 
predicted. Internationality was measured using an index of the expected spread or spatial diversity of the problem each research theme is to address. Sustainability was measured using a subjective index from 1 to 5 in accordance with the expected contribution of the research to sustainable agriculture. These four indices were then normalized, weighted and combined into a single composite index.

\section{Distilling existing knowledge}

A considerable amount of information usually exists within the organization itself or among its NARS partners that will be useful in developing a database of relevant supply-side factors. Information on the extent and severity of crop-related problems and their tractability, for example, is part of the databank which resides in these institutes, albeit often in unassembled and hence unusable form. This information can form the basis for an assessment of the potential impact of different research themes. Thus, a major activity of a coordinating body such as the Working Group is tapping the expertise within the institute as a means to developing its information database.

In this exercise, primary data provided by scientists inside and outside the organization (e.g. estimated yield losses for biotic and abiotic constraints in the various regions) ${ }^{3}$ and secondary data (e.g. number of poor and female illiterates per region, crop area and production, current prices, etc.) collected from numerous sources were used to develop a database to assist management in setting research priorities. This database can now serve as the core of a more comprehensive database management system on which future analyses and decision support will depend.

\section{Interactive decision making}

Prioritizing research themes implies making choices. The more transparent the method, the easier it is to rally support for decisions taken. In the course of developing a five-year research plan, activities such as scientists' meetings, brainstorming sessions and institute-level forums help ensure ongoing dialogue between scientists, members of the Working Group, and management. For ICRISAT, the range of such deliberations were wide: regular meetings of the Working Group; five days of institute-wide forums for discussion of MTP methodology and proposed research themes; ad hoc meetings with program directors, executive directors, consultants, and other management committee members; and many other meetings at the program, group and unit level where nearly 150 scientists prepared and presented research proposals for 1994-98. 
Such exercises produce valuable 'institutional' spillovers: an overall high level of communication improves esprit de corps, and new linkages are formed among scientists across disciplines and locations. The broad knowledge base within the institute increases, which facilitates genuine appreciation of fellow scientists' activities.

\section{THE SCORING MODEL: A WEIGHTED, COMPOSITE INDEX}

Four items reflect most closely the research goals of the CGIAR system as articulated in mission and mandate statements: efficiency, equity, internationality and sustainability. They were sclected as the key parameters against which likely impact would be assessed. Net benefit-cost ratio, numbers of poor and numbers of adult female illiterates in the research domains where the theme is focused, the Simpson Index of Diversity and a 1-5 sustainability rating scale were chosen as proxy measures. Values must be calculated for these measures using information from research protocols ('themes') and other databases (see the next section). Themes can then be ranked from highest to lowest with respect to any one specific measure. However, since themes are evaluated for impact using multi-objective criteria, some means of integrating the various measures is indispensable.

The ideal theme has large expected benefits relative to the cost of investment, affects a large number of poor, is widely pervasive, and is environmentally friendly. For two criteria, efficiency and equity, themes which offer a high rate of return and which simultaneously affect a large number of people in poverty are preferred. This is depicted in Fig. 1 as the

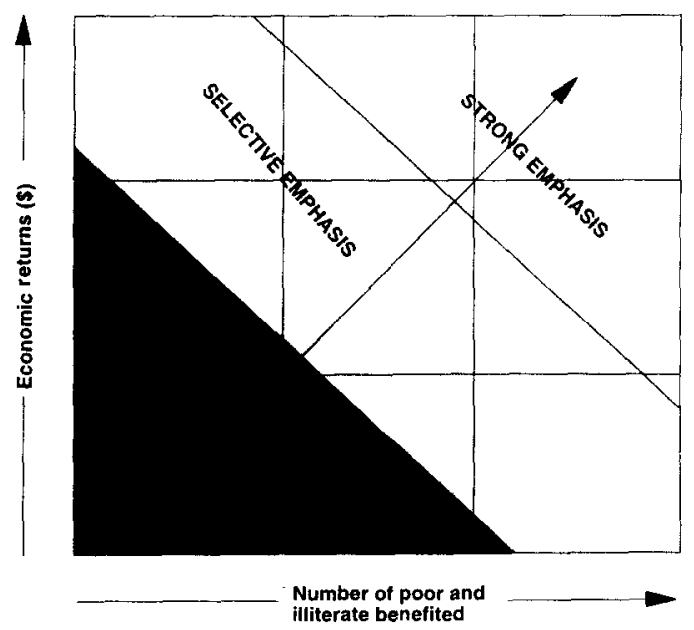

Fig. 1. Research portfolio selection: potential trade-offs between returns and equity. 
area that should receive 'strong emphasis'. Yet in many cases there are trade-offs, e.g. a project impacts on a large number of poor, but offers only low rates of return on investment. Thus, it is usually necessary to array the efficiency and equity trade-offs which are involved in the choice of any particular research portfolio. This is feasible where only two criteria are concerned; it becomes more problematic with three or four. Ultimately, in establishing the relative importance of each criterion in setting priorities, some explicit weighting procedure is necessary.

The basis for assigning weights to the criteria must be justified and transparent. In this case, because each of the four criteria addresses a fundamental goal of the organization, none could be ranked over another. After considerable discussion, it was decided to give equal weight to each of the four criteria, with poverty and female illiteracy each accounting for $50 \%$ of equity, or $12.5 \%$ of the total. With weights assigned, it is possible to construct a composite index. However, before these measures can be integrated into a single model, values for each of the measures must be 'normalized' to account for potential bias in the magnitude and distribution of each variable. For example, in this particular case, net benefit-cost ratios varied between near zero and 135 , whereas sustainability values ranged between 1 and 5. Normalizing each of the measures by transforming all values into a $0-1$ range corrects for this bias. The highest figure observed for each criterion serves as the reference point and is given a value of 1.00 . All other (lower) values in that criterion are normalized from this value, i.e.are derived by taking the actual values and dividing by the highest figure. Thus, normalized sustainability values of $0.00,0.25$, $0.50,0.75$ and 1.00 correspond to original scores of $1,2,3,4$ and 5 , respectively. Similar procedures were carried out for other measures, with some modifications. ${ }^{4}$

The additive model allows a score to be calculated for each theme as follows: ${ }^{5}$

$$
C l_{i}=X_{1 i}+0 \cdot 5 X_{2 i}+0 \cdot 5 X_{3 i}+X_{4 i}+X_{5 i}
$$

where $C l_{i}$ is the composite index score for theme $i$ and $X_{1 i}, X_{2 i}, X_{3 i}, X_{4 i}$ and $X_{5 i}$ are theme $i$ normalized values for net benefit-cost ratio, numbers of poor, numbers of female illiterates, internationality and sustainability, respectively. For each of the prospective research themes identified, a composite index score can thus be calculated.

Although 'equal weights' are applied in the scoring model, the trade-offs between the different criteria are by no means 'equal'. This warrants a closer look. In Table 1 , five normalized values $(1 \cdot 00,0 \cdot 75,0 \cdot 50,0 \cdot 25,0 \cdot 00)$ and their corresponding actual values for each of the four criteria (five 
TABLE 1

Equivalences of Actual and Corresponding Normalized Values for Each of the Four Criteria

\begin{tabular}{|c|c|c|c|c|c|c|c|c|c|}
\hline \multirow{2}{*}{\multicolumn{2}{|c|}{ Benefit-cost ratio }} & \multicolumn{4}{|c|}{ Equity (millions of) } & \multirow{2}{*}{\multicolumn{2}{|c|}{$\begin{array}{l}\text { Internationality } \\
\text { (Simpson Index) }\end{array}$}} & \multirow{2}{*}{\multicolumn{2}{|c|}{$\begin{array}{l}\text { Sustainability } \\
\text { ranking }\end{array}$}} \\
\hline & & \multicolumn{2}{|r|}{ Poor } & \multicolumn{2}{|c|}{ Female illiterate } & & & & \\
\hline Actual $\Lambda$ & Normalized & Actual & Normalized & Actual & Normalized & Actual & Normalized & Actual & Normalized \\
\hline 50 & 1.00 & 250 & $1 \cdot 00$ & 300 & $1 \cdot 00$ & 1.00 & $1 \cdot 00$ & 5 & 1.00 \\
\hline $37 \cdot 5$ & 0.75 & $187 \cdot 5$ & 0.75 & 225 & 0.75 & 0.75 & 0.75 & 4 & 0.75 \\
\hline 25 & 0.50 & 125 & 0.50 & 150 & 0.50 & $0 \cdot 50$ & 0.50 & 3 & 0.50 \\
\hline \multirow[t]{2}{*}{$12 \cdot 5$} & 0.25 & $62 \cdot 5$ & 0.25 & 75 & 0.25 & 0.25 & 0.25 & 2 & 0.25 \\
\hline & & & & & & & & 1 & 0 \\
\hline Weights & 1 & & 0.5 & & 0.5 & & 1 & & 1 \\
\hline
\end{tabular}

components) are given. In order to achieve a 0.25 increase in the composite index score a research theme would have to either (a) increase its net benefit-cost ratio by 12.5 , (b) increase the number of poor affected by 62.5 million and the number of female illiterates affected by 75 million, (c) increase the Simpson Index of Diversity by $0 \cdot 25$, (d) increase sustainability score by 1 , or (e) increase any fractional combination thereof. The additive composite index model is indifferent between those changes. Identified

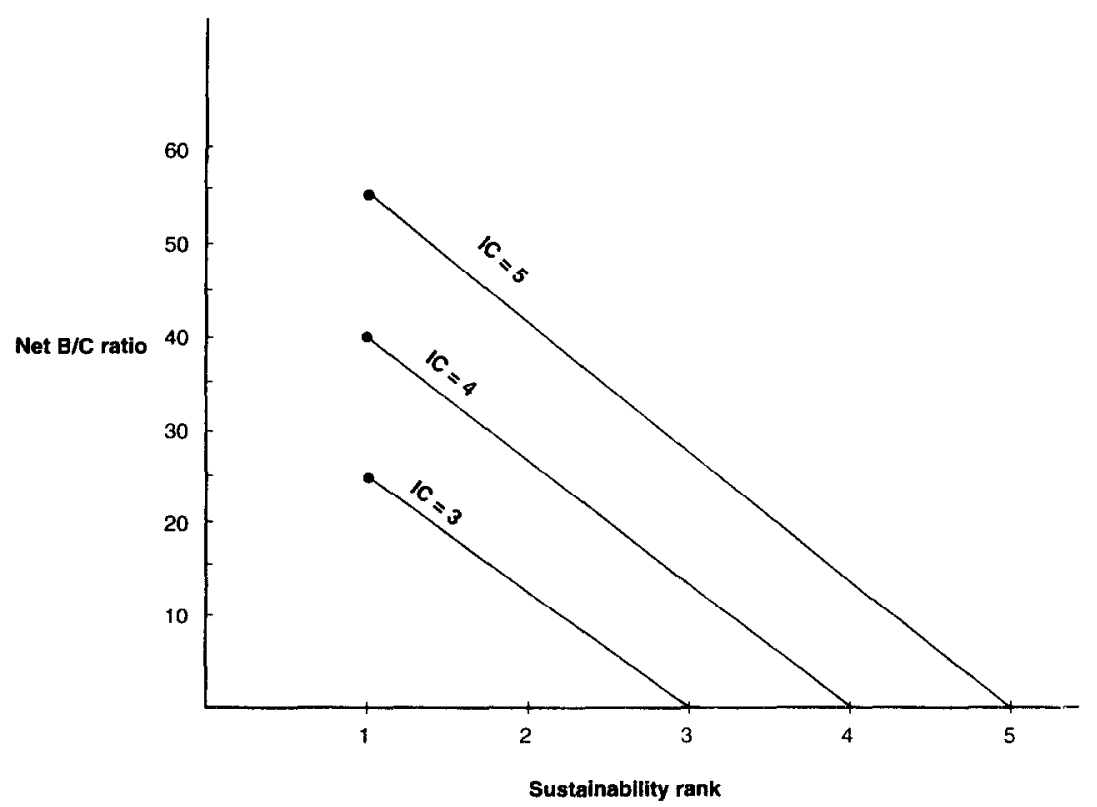

Fig. 2. Indifference curves (equivalent trade-offs) between $\mathrm{B} / \mathrm{C}$ ratio and sustainability. 
here is a set of indifference curves uniquely defined by three things: the distribution of the actual values of each criterion, the value used to normalize, and the weights assigned to each component in the additive model. Figure 2 shows the indifference curves (IC) for two criteria - four criteria would require a four-dimensional space. The $\mathrm{IC}=3$ line represents the combinations of net benefit-cost $(\mathrm{B} / \mathrm{C})$ ratios and sustainability scores for which the decision maker is indifferent, i.e. all achieve the same level of utility (composite index).

How accurately do these indifference curves reflect the judgements about trade-offs made by the decision makers? Is a net gain of 12.5 in the net $\mathrm{B} / \mathrm{C}$ ratio truly equivalent to an increase of 0.25 on the internationality scale? The model used here indicates so. Clearly, in order to achieve a more 'preferred' outcome, it would be necessary to elicit from decision makers the trade-offs they are willing to accept between the different measures of benefit. For example, decision makers would have to indicate how many units of net $\mathrm{B} / \mathrm{C}$ ratio they would be willing to forego if they could effectively reach 50 million more pcople in poverty, and how many units of net $\mathrm{B} / \mathrm{C}$ ratio to raise the internationality index by $0 \cdot 10$, and so on. All possible trade-offs between the four benefit measures would have to be known. Ideally, such preferences should be elicited beforehand and form the basis for weights in the model once distributions of the measures are known.

\section{DEVELOPING THE PLAN}

In actually developing the research plan, the steps in conceptualization, operationalization and quantification often proceed in an iterative fashion. This includes everything from research domain definition to research theme development, and from the specification of scientific outputs to estimation of expected economic and social impact.

\section{Working definitions}

The concept of a research domain is fundamental in assessing potential regional research impacts and spillovers. TAC's classification uses nine broad agroecological zones (AEZ), derived from the Food and Agriculture Organization (FAO) agroecological zones classification (FAO, 1978-81). This division is based on the length of the growing season largely a function of the dominant agroclimatic characteristics - and temperature conditions. Crop improvement scientists, however, sometimes find it difficult and of limited use to relate their research themes directly to 
AEZ domains, as they are defined (ICRISAT, 1992b). In the search for more appropriate agricultural domains by which to delineate research, a new interpretation of the 'research domain' has emerged.

AEZ domains have sometimes been used synonymously with research domains, or at least as a conceptual basis for specifying research domains. The definition can be taken one step further. The chosen concept of research domain is analogous to the concept of the Centro Internacional de Mejoramiento de Maiz y Trigo (CIMMYT) of recommendation domain (Byerlee et al., 1980). However, where recommendation domains relate mainly to adaptive and applied research, research domains relate more to strategic and basic research, which is more relevant when assessing international agricultural research prioritics. Thus, a research domain is defined as a relatively homogeneous region where the relevance of strategic research is expected to be pervasive, i.e. have impact throughout that region.

Production systems and yield constraints are the primary criteria for defining research domains. Domains are defined from the perspective of the scientist and the research objective rather than only using agroclimatic-based criteria. Rainfall, soils and latitude alone, or together, do not necessarily specify a research domain - as it is defined here, i.e. what is relevant for research purposes. It may be that the uses of the crop (e.g. grain versus fodder) and not growing conditions per se are of more relevance for some types of research planning. Other important characteristics of research domains include the season (e.g. rainy versus post-rainy), the maturity group and yield constraints. Crop-improvement scientists often think in terms of particular regions which are best adapted to particular traits or characteristics of a crop, hence the term 'zones of adaptability'. Between five and eight domains were defined for each mandate crop during this planning phase at ICRISAT. Their characterization with respect to production system, major constraints, and location (and map depictions) appear in ICRISAT (1992b).

Soil-, water- and crop-management scientists are often more comfortable using a classification system akin to the AEZ where research domains are agroclimatically-based. Six major soil $\times$ rainfall groups were identified for India, for example, in the course of this exercise, based on earlier work by von Oppen et al. (1985). Work continues on trying to improve and sharpen the definition of crop-based and agroclimatically-based domains with a view to integrating these into a standard set of production systems.

\section{Data requirements}

Once domains are identified, data for each domain can be gathered on population, absolute numbers of poor, female literacy rate, crop production, 
crop production value, crop losses per constraint, economic losses, and yield and potential economic recovery through research.

\section{Socio-economic data}

Information on many socio-economic variables can be derived from sources such as the World Bank (1992), United Nations Development Program (UNDP) (1992), and Broca and Oram (1991). Some estimation and interpolation are required as research domains will seldom correspond to national boundaries. Although most data are available only at the country level, reliable data do exist at regional, state or district level for some countries, e.g. India.

World market prices are used to assess the value of crop production loss and gain. For primarily food grain crops like millet and sorghum - as distinct from feed grains that are generally not traded on the world market major producer country prices can be used (e.g. Govt of India, 1990). In some cases prices need to be adjusted to account for trade and price distortions. Production value must also take into account the crop by-product component. Since these products are rarely, if ever, traded on the world market, prices must be taken from local markets or village level surveys.

\section{Production data}

Crop production data can be derived from FAO Production Yearbooks (FAO, 1992) and from individual country crop reports for regional and state-level data (e.g. Govt of India, 1992). Again, adjustments are sometimes necessary in facilitating aggregation and consolidation at the research domain level.

\section{Yield losses}

Crop losses resulting from abiotic and biotic constraints may be estimated by the scientists themselves (or 'expert councils') where formal data based on survey results are not available. Preliminary estimates will usually be made by the individual scientists, but ideally, final estimates should come via group consensus. Estimates are best expressed as percentages of average yields (farmers' fields, not experiment station) currently achieved in each respective country, ${ }^{6}$ i.e. the percentage increase in farmers' yields that would be expected in the absence of a particular constraint - all other constraints still operating. This represents the full yield gap for that particular constraint.

\section{Yield recovery}

In most cases it is unreasonable to assume that research alone can alleviate the total impact of a particular constraint on crop yields. The next step, 
therefore, is to estimate the likely yield gains achievable from research. In the first instance, a single-constraint approach is advised - estimating the percentage yield improvement expected by partially addressing constraints via successful research. The critical question, therefore, is 'what percentage of the total yield gap is economically recoverable'? Resolution of constraints should be considered by the most promising method: varietal development, crop management, or both (see Fig. 3).

Obviously, breeders hope to incorporate resistance to more than just a single constraint when developing superior breeding material for release to the NARS. Similarly, resource-management scientists focus on systems, and a multitude of interacting components in the field. Recognizing this, an attempt should be made to partition out the respective contributions from resolving each singular constraint. Thus, the total yield improvement from introducing improved material into farmers' fields is often attributed to resolving several constraints simultaneously, e.g. drought-tolerant, insect-resistant cultivars. The challenge is to separate out these effects and attribute expected benefits accordingly. Interactions - synergistic and antagonistic effects - must also be considered and estimated, allowing for research theme 'spillover effects'. ${ }^{7}$ Potential spillover of benefits to other regions and synergistic effects by simultaneous resolution of two or more constraints should be taken into account. Note that the estimates of

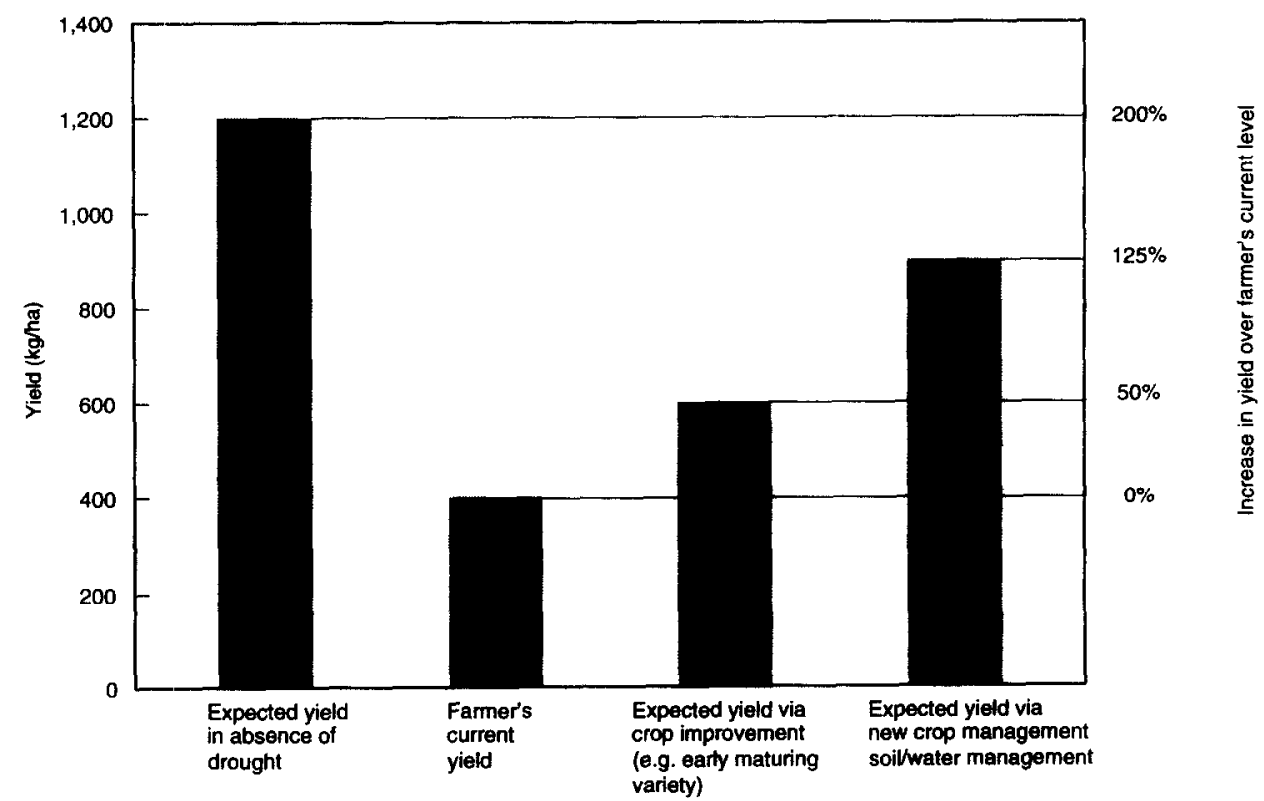

Fig. 3. Estimated yields of pigeonpea under various production scenarios (hypothetical). 
expected yield gains are given in the context of the research being proposed in the research protocols.

\section{Research protocols}

The next step is to transform constraints and associated yield losses into research themes and expected outputs. This is where teams of scientists must consider which constraints can best be overcome by research - in other words, where lie the best opportunities for success. Of the many constraints identified, a limited number of researchable topics will be identified.

For each research theme identified a research protocol, or theme descriptor, is generated by the respective scientists concerned. The protocols cover 14 items which provide the qualitative and quantitative information necessary to characterize, and ultimately, evaluate themes: constraint/problem, crop(s) involved, research domain, type of research, research output, research and extension lags, adoption ceiling, probability of success, senior scientist years, yield improvement expected, production costs, stability component, environmental/sustainability contribution, and extra capital requirements (see Appendix for details).

Data can be collected considering several staff and resource scenarios, e.g. a minimum and an optimum of scientific staff assigned to the theme. Thus, research outputs and corresponding lags, expected yield improvement, probabilities of success and senior scientist years will vary according to the scenario. In this case, minimum and 'less-constrained' resource scenarios were considered and the more efficient of the two chosen.

\section{MEASURING IMPACT}

\section{Economic value of the research}

For each research theme - generally encompassing several research domains - estimates can be made of the expected economic value of the research taking into account predicted yield gains, probabilities of success, research lags, the adoption lag, ceiling levels of adoption, scientist staff requirements and incremental capital costs of research. ${ }^{8}$ Figure 4 depicts the nature of the research-adoption lags built into the framework.

To estimate the economic value of each proposed research theme, discounted net benefit-cost ratios can be calculated following methods commonly used in project analysis for estimating project worth (see Gittinger, 


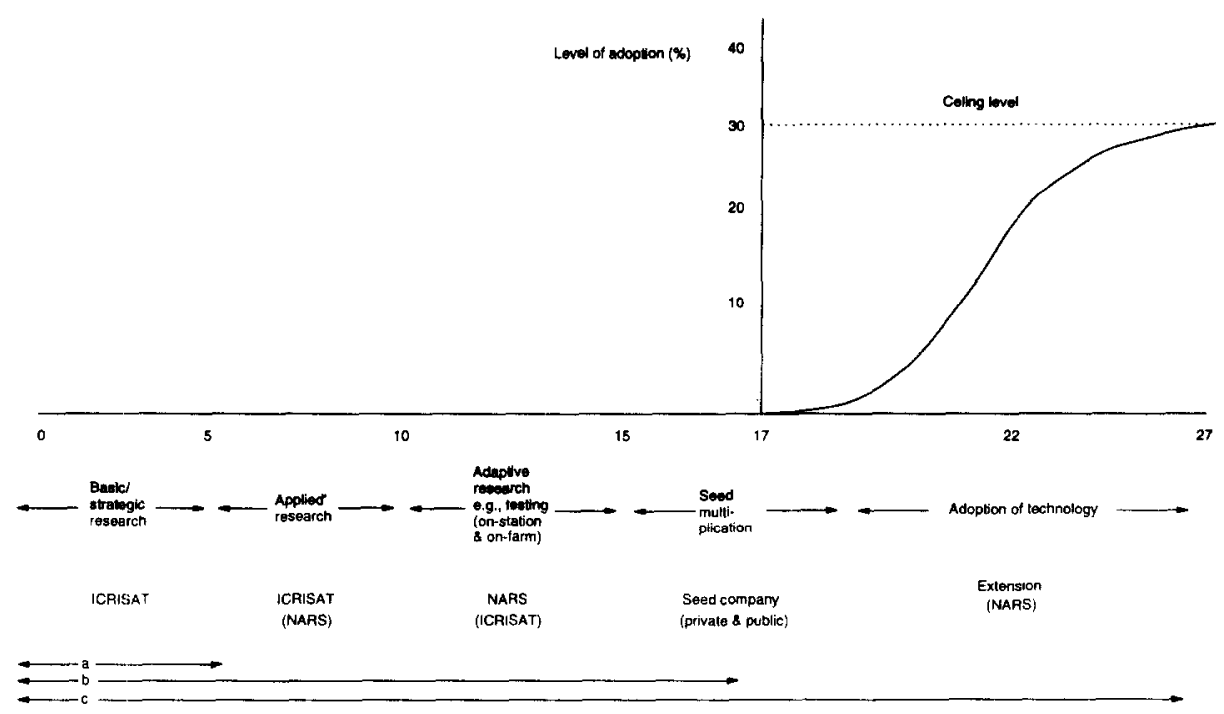

Fig. 4. Research and adoption lags (chickpea wilt complcx example).

1982). Economic benefits can be measured by valuing the various products of research emanating from successful research projects. If utilized, these research products can lead to the development of new crop technology, which in turn, if adopted, results in improved crop performance. A necessary condition for new technology adoption is lower production costs per unit of output. New technology which increases the marginal product of inputs and increases elasticity of substitution among inputs will only be exploited if incremental input costs are initially less than the value of the marginal product (Fox, 1987). Improved crop performance usually - but not always - translates into increases in crop production. ${ }^{9}$ If adopted on a large scale, this increase in crop production can be significant, and it can be valued, given some assumptions about market prices.

For many analyses, the small country case of perfectly elastic demand can be assumed. Each country is considered a price taker in the world market, i.e. gains in production through the use of the new technology are not large enough in any single case to significantly affect world market prices. ${ }^{10}$ In addition, production inputs are assumed to be available in perfectly elastic supply. The validity of these assumptions depends on the structure of the product and input markets and in particular the influence of domestic agricultural policies. ${ }^{11}$ Given these assumptions, the change in total net benefit can be measured as yield gain times area times price minus incremental production costs. 
Region-specific distribution of expected productivity increases is provided in the research protocols and thus an estimate of the undiscounted economic value of success can be determined. Net present value of the benefit is calculated by accounting for probabilities of research success, expected delays in benefit streams due to research and adoption lags, and estimates of the adoption path and ceiling level of adoption. A $10 \%$ social rate of discount was used to calculate present values of benefit and cost streams.

Grain yield is not the only benefit derived from improved crop performance. Fodder yields often increase as well. Estimates of fodder yield increases are considered and valued according to current prices in major producing countries.

Thus, unadjusted and undiscounted economic benefits are estimated as

$$
E B_{i k t}=\left[\left(y_{i k g} * P_{k g}\right)+\left(y_{i k f} * P_{k f}\right)-c_{i k t}\right] A_{k t}
$$

where $E B_{i k t}$ is the undiscounted economic benefits derived from new technology $i$ on crop $k$ in year $t, y_{i k g}$ and $y_{i k f}$ are the per hectare incremental (average) grain and fodder yield improvements expected on farmers' fields due to adoption of technology $i, P_{k g}$ and $P_{k f}$ their respective prices, $c_{i k t}$ are the per hectare incremental costs associated with adoption of technology $i$ and $A_{k t}$ is total area of crop $k$ in the relevant research domain.

After adjustment for probabilities of success, adoption, and the social rate of discount, economic benefits can be described in terms of a net present value (NPV),

$$
N P V_{i k t}=\frac{E B_{i k t} * P r_{i} * A d_{i t}}{(1+r)^{t}}
$$

where $N P V_{i k t}$ is the net present value of the gross economic benefits derived from technology $i$ on crop $k$ in year $t, P_{i}$ is the probability of success in research leading to the development of technology $i, A d_{i t}$ is the percentage adoption of technology $i$ by farmers in year $t$, and $r$ is the social discount rate. Total net present value of the gross economic benefits for technology $i$ on crop $k$ can then be described as the sum of all period net present values, i.e.

$$
N P V_{i k}=\sum_{t=1}^{n} N P V_{i k t}
$$

This value cannot, strictly speaking, be attributed solely to the research done by the institute. Other inputs into the research and adoption process 
are critical, e.g. NARS research, public/private seed companies, agricultural extension and infrastructure development. In this case, the benefit of the value of the research at the margin has been estimated. In other words, the $N P V_{i k}$ is equivalent to the benefit foregone (opportunity cost) of, in this case, ICRISAT not being involved in the research. The other inputs in the process can be regarded as largely fixed costs in the short term.

These benefits are the estimated gross benefits. Investment costs have not been subtracted. In general, costs are easier to identify and value than benefits. The single largest cost to consider is human capital: the scientists themselves and their administrative and research support staff. The scientific staff required for each theme identified is given by discipline and by year and includes portions of ICRISAT scientists' time where appropriate. Standard costs are used in valuing scientists' time based on historical costs. The total operating budget of the institute can be divided by the number of internationally recruited scientists on board at that time to arrive at an estimate of direct research and research-related costs per scientist per year. Research-related costs include library, farm management, and general administrative and overhead support; it also includes capital depreciation. Special high-value capital items $\left(k_{t}\right)$, e.g. electron microscope, required for research themes are treated separately.

The discounted stream of cost flows for technology $i$ and crop $k$ are calculated as

$$
C_{i k}=\sum_{t=1}^{n} \frac{\left(S Y_{t} * S C\right)+K_{t}}{(1+r)_{t}}
$$

where $C_{i k}=$ discounted costs associated with technology $i$ on crop $k$, $S Y_{t}=$ total number of scientist years in year $t, S C=$ standard scientist (institute) cost per year, $K_{t}=$ special capital costs in year $t, t=1,2, \ldots, n$, $r=$ discount (or interest) rate.

There are sunk costs which were incurred in the past on which new project themes are now based. These are not included in the cost estimation for new projects. Project analysis is concerned only with the rate of return on future investments.

Once the discounted stream of benefits and costs are appropriately valued, calculating the net benefit-cost $(B / C)$ ratio is a straightforward exercise from eqns (3) and (4):

$$
\text { Net } \mathrm{B} / \mathrm{C} \text { ratio }=\frac{N P V_{i k}}{C_{i k}}
$$

Again, since non-ICRISAT costs are not included in the investment valuation, the net $B / C$ ratio measures only the return at the margin, and is 
not strictly speaking a proper measure of economic benefits to society at large. This does not, however, invalidate its use as a planning device for the institute where the aim is for an ordinal ranking of research themes.

If the sole objective of research investment policy was to maximize economic benefits from agricultural research, themes could be ranked by net $\mathrm{B} / \mathrm{C}$ ratios in descending order. Themes at the top of the list would receive highest priority. In most cases, however, research objectives include both economic growth and less tangible benefits from research. Their intangibility does not make them less important - only more difficult to assess. While the net $\mathrm{B} / \mathrm{C}$ ratio is a (proxy) measure of economic efficiency, it does not address the issue of how benefits are distributed to different groups in society (equity), or different countries (internationality), or how the environment will be affected (sustainability).

\section{Equity}

For publicly funded rescarch institutions, consideration of the distribution of the economic gains from research is at least as important as the size of the gains themselves.

\section{Poverty}

In pursuing the goal of social justice, project themes which specifically target those most at risk, particularly those in poverty, should be given higher priority. ${ }^{12}$ However, it is not a simple exercise identifying the poor, nor tracking benefits accruing to them. In this analysis, the number of poor in those research domains where benefits are expected to flow and achieve impact were considered. ${ }^{13}$ Time and data limitations did not permit a more rigorous determination of potential benefits to the poor by disaggregating consumer and producer surplus by social group. Even with this simplification, many questions remain: who are the poor? How is poverty best defined? Where are the poor located? And what are their numbers?

Various measures of poverty have been used in the literature. The traditional headcount index uses a poverty measure based on the number of people below a designated poverty line. The poverty line is usually some critical minimum value with respect to per capita income or calorie consumption. Although widely used, this measure is often criticized because it fails to capture the depth of poverty dimension, i.e. how poor the individuals below the cut-off line are. ${ }^{14}$ In this study, a combination of two measures was used to capture the equity/poverty variable: (1) headcount of poor, defined as the number of people with income below the minimum level required to maintain an acceptable calorie consumption level, and 
(2) the extent of female illiteracy, a gender variable but also a good proxy for general welfare.

\section{Gender}

The use of household income and expenditures per capita by itself to define poverty - even as a simple headcount measure - has serious drawbacks. It fails to capture dimensions of welfare such as health, life expectancy, literacy, and access to public goods or common property resources (World Bank, 1990). Furthermore, estimates of this measure are often accompanied by large margins of error. Therefore, the household income and expenditure-based poverty measure was combined with another poverty indicator, the female illiteracy rate, to obtain a more comprehensive index of welfare. Studies have shown that the education of women is associated with higher incomes, better child care and nutrition, and lower infant mortality (World Bank, 1989; Cochrane, 1980). Indeed, according to some experts, female illiteracy rate is one of the best single indicators of overall general human welfare (Sudarshan, R., UNDP, pers. comm., 1991).

Data on absolute numbers of poor by country and by agroecological zone were taken from an International Food Policy Research Institute (IFPRI) study by Broca and Oram (1991). Numbers of illiterate adult females $^{15}$ were compiled based on data from the UNDP Human Development Report (1992), Vu (1984), United Nations Educational, Scientific and Cultural Organisation (UNESCO) (1985) and Indian census statistics (Govt of India, 1985). These data provided the basis for numbers of poor and numbers of illiterate adult females which were extrapolated for each research domain. The figures are therefore considered notional, not precise. Lastly, aggregating across research domains for a given research theme provides an estimate of the numbers of poor and female illiterates in the regions where the expected benefits are targeted.

\section{Internationality}

International agricultural research institutes have a complementary role to play in carrying out research on topics of regional and global importance. Agroecological environments are not confined to national boundaries; neither are the major crop constraints nor their solutions. Herein lies the most compelling reason for carrying out agricultural research at the international level: opportunities for geographical spillover normally not captured by national research organizations. There are numerous cases wherein a single country is unable to capture the full economic gains from 
research, as they must bear all the costs but reap only a portion of the benefits. Other countries may be in a similar position, so that an international research effort would be justified. International agricultural research - and its benefits - are clearly world public goods. An international center's comparative advantage, then, is in undertaking research whose relevance is widely pervasive.

The cross-national character of a theme, therefore, should be a prominent feature in determining an international research center's priorities. As a measure of internationality, the potential geographical spillover benefit from research, the Simpson Index of Diversity was used:

$$
D_{i}=1-\sum_{j=1}^{J}\left(S_{i j} / 100\right)^{2}
$$

where $D_{i}=$ diversity value ranging between 0 and 1 , and $S_{i j}=$ share of total production gain resulting from research theme $i$ in country $j$.

Higher values correspond to research themes which are morc international in scope. Table 2 shows a comparison of Simpson Index values for

TABLE 2

A Comparison of Simpson Diversity Indices for two MTP Research Themes

\begin{tabular}{|c|c|c|c|}
\hline \multicolumn{4}{|c|}{ Crop } \\
\hline \multicolumn{2}{|c|}{ Sorghum } & \multicolumn{2}{|r|}{ Pigeonpea } \\
\hline \multicolumn{4}{|c|}{ Theme } \\
\hline \multicolumn{2}{|c|}{ Sooty stripe } & \multicolumn{2}{|c|}{ Sterility mosaic } \\
\hline Country & $\begin{array}{l}\text { Expected production } \\
\text { gain }(000 t)\end{array}$ & Country & $\begin{array}{l}\text { Expected production } \\
\text { gain ('000 } t)\end{array}$ \\
\hline Mali & $0 \cdot 70$ & India & 941 \\
\hline Chad & 0.65 & Nepal & 4 \\
\hline Sudan & $4 \cdot 00$ & Mynamar & 4 \\
\hline Cameroon & 1.00 & Kenya & 20 \\
\hline Burkina Faso & $2 \cdot 95$ & Uganda & 6 \\
\hline Nigeria & 6.75 & Malawi & 18 \\
\hline Ethiopia & $1 \cdot 25$ & Nigeria & 8 \\
\hline Niger & $0 \cdot 50$ & Mozambique & 4 \\
\hline Total & $17 \cdot 80$ & Total & 1005 \\
\hline Simpson Diversit & Index $\quad 0.77$ & & $0 \cdot 12$ \\
\hline
\end{tabular}


two ICRISAT MTP themes: sooty stripe in sorghum and sterility mosaic in pigeonpea. Pigeonpea production, being highly concentrated in one country (India), results in a low score for the sterility mosaic theme.

\section{Sustainability}

While most people feel they have a sense for the concept, the likely contribution of alternative research themes to sustainability is difficult to measure. While good attempts have been made to quantify sustainability (Lynam \& Herdt, 1988; Ehui \& Spencer, 1990), the concept remains elusive. However, the prominence of ecological considerations has now brought an explicit focus on sustainable improvements to agricultural research.

Where objective evaluation is not possible, subjective judgements must suffice. In this case, themes were ranked from 1 to 5 according to their likely impact in maintaining or upgrading the resource base to ensure long-term productivity. A 1 indicates no, or only negligible, contribution to sustainable agriculture; a 5 indicates upgrading the resource base is the primary focus of the research. No rigorous formula was used. ${ }^{16}$ Rather, arguments were put forward to explain how a particular piece of research was expected to change the resource base or system of management that in turn would impact favorably on long-term productivity growth. Both environment and human health impacts were included. Thus, research to identify standards and policies that limit the unwise use or degradation of natural resources has sustainability as its primary focus. Pest resistance via crop improvement in pigeonpea scored relatively high on the 1-5 sustainability scale because development of insect-tolerant cultivars would have a dramatic impact on the use of pesticides (widely and intensively used at present). In contrast, research to combat stemborer in sorghum (a major yield reducer) scored low on sustainability, since resistant cultivars would not bring with them any specific improvement in the resource base, or reduction in dependence on chemicals, since pesticides are not presently used to control this insect. ${ }^{17}$

\section{Other indicators considered}

Other criteria can also be considered for possible inclusion in a prioritysetting exercise. Food security, defined as the continuous availability of an adequate food supply for the inhabitants of a particular geographic region or country, is a viable candidate and was considered initially. The indicator of self-reliance is often measured by food import gap in the year 2000 (Ezekiel, 1989). ${ }^{18} \mathrm{~A}$ better proxy to food security might be the relative importance of a commodity in the regional (or national) economy, 
i.e. how dependent a region is on a given commodity. This variable comes closer to capturing the essence of food security than does the need for food aid. Due to time and data availability constraints this indicator could not be included in the final criteria. More work is needed in identifying appropriate measures of food security.

Strength and commitment of NARS is another criterion to consider. While this variable should be (and is) factored into other programs, e.g. human resources development, it may not greatly influence the relative ranking of priority research themes. Furthermore, there are offsetting perspectives to consider. In general, a strong NARS implies efficiency advantages whereas weak NARS may have an equity justification.

Stability, the extent to which the proposed research theme will reduce yield variability, was also considered. This criterion, similar to sustainability, can be measured on a subjective $1-5$ scale. While there are singular instances where this aspect could be critically important, it was decided that stability should not be a primary discriminating factor in setting ICRISAT's research priorities.

\section{ESTABLISHING THE PRIORITY SEQUENCE}

For each of the proposed research themes, an overall score can be calculated using the weighted, additive composite index scoring model described earlier. Subsequently, an ordinal ranking of themes emerges.

\section{Consolidation, deletion and ranking}

Prior to generating a final ranking, senior research management should scrutinize all themes together for two additional considerations: consolidation and elimination. While there may be significant inter-location dialogue throughout the planning process, most of the interaction inevitably occurs between scientists at single locations. Hence, there is a need for research directors/managers to consolidate or merge themes where possible and thereby gain further economies of scale.

There may also be themes for which the institute does not have a comparative advantage. Existing criteria such as net benefit-cost ratio and internationality already scan for such considerations, but there are other aspects equally important to this criterion: who are the other private or public global and local suppliers of research and to what extent does the institute have an advantage over them in carrying out specific types of research? Activities should be restricted to those areas of research which look promising and which other suppliers of research outputs are not able 
or not willing to take up. For example, some of the applied and adaptive research effort required in Asia, although likely to reap high returns during the next few years, is probably best left to the national programs. CGIAR centers should focus on problems of a more strategic nature there.

Using the composite index scores for the final consolidated research themes, an institute-wide ranking can be generated, thus establishing priorities for the organization during the planning period.

\section{The research portfolio plan}

The ranked sequence of research themes and their estimated costs (including rescarch and non-research) for ICRISAT's MTP cxercise are given in Table 3. Cumulative costs are also provided at each point along the ranked list of themes. The final research portfolio - the selected research themes and activities planned for a given period - depends, ultimately, on the final budget allocation.

One of the valuable exercises carried out at this stage is estimating foregone benefits under various plans. For example, if ICRISAT receives a $\$ 27.42$ million budget instead of $\$ 30.18$ million, foregone benefits are those emanating from themes 81 through 92 - those not included in this research portfolio. The estimated NPV from just eight of those 12 themes (four were economics themes for which $N P V$ was not estimated) was $\$ 62.8$ million. $\$ 62.8$ million is the potential benefit stream lost if an additional annual investment of $\$ 2.76$ million for core research for the next five years is not made available to ICRISAT. The foregone benefits in terms of numbers of poor and female illiterates, the internationality effect and impact on sustainability were similarly calculated (see ICRISAT, 1992b). Themes higher up on the priority sequence imply proportionately higher foregone benefits per research dollar withheld, i.e. the marginal value product of each theme increases as one moves up the ranked sequence. Such a listing of the priority sequence of research themes makes choices transparent to all stakeholders, including donors and NARS, and is a major advantage of this approach.

\section{INSTITUTIONAL IMPACT AND BIAS}

Internal reaction to such planning exercises is most often positive, particularly regarding the process if it is characterized by genuine openness. Scientists want to be involved and help shape their research agenda. As for the results, not unexpectedly, there are favorable and unfavorable reactions, depending on the net effects on individual programs and scientists. 
TABLE 3

ICRISATs Portfolio of (Ranked) Research Themes

\begin{tabular}{|c|c|c|c|c|c|c|}
\hline \multirow[t]{2}{*}{ Rank } & \multirow{2}{*}{$\begin{array}{l}\text { Pro- } \\
\text { gram }\end{array}$} & \multirow[t]{2}{*}{ Center(s)/location(s) } & \multirow[t]{2}{*}{ Constraint/theme } & \multicolumn{3}{|c|}{ Efficiency } \\
\hline & & & & $\begin{array}{c}N P V \\
(\text { Smil })\end{array}$ & $\begin{array}{c}\text { Net } \\
B / C \\
\text { (ratio) }\end{array}$ & $\begin{array}{l}I R R \\
(\%)\end{array}$ \\
\hline \multicolumn{7}{|c|}{ Core funding } \\
\hline 1 & GRÜ & IC & Germplasm evaluation & $79 \cdot 1$ & 101.9 & - \\
\hline 2 & GRU & IC & Germplasm collection & $24 \cdot 5$ & $40 \cdot 7$ & - \\
\hline 3 & LGM & IC & Drought-CP & $265 \cdot 2$ & $113 \cdot 7$ & $47 \cdot 3$ \\
\hline 4 & GRU & IC & Germplasm maintenance & $15-3$ & $35 \cdot 5$ & - \\
\hline 5 & LGM & IC & Ascochyta blight-CP & $73 \cdot 2$ & 134.7 & $64 \cdot 0$ \\
\hline 6 & LGM & IC/ISC/SADCC & Rust-GN & 80.9 & $47 \cdot 9$ & $33 \cdot 0$ \\
\hline 7 & LGM & IC & Aflatoxin-GN & $7 \cdot 6$ & $23 \cdot 1$ & $29 \cdot 3$ \\
\hline 8 & LGM & IC/ISC/SADCC & Late leaf spot-GN & $32 \cdot 7$ & $12 \cdot 4$ & 24.9 \\
\hline 9 & LGM & IC/ISC & Aflatoxin (MGT)-GN & $19 \cdot 7$ & 6.4 & 23 \\
\hline 10 & LGM & IC & Insect damage-CP & $76 \cdot 1$ & $78 \cdot 5$ & $47 \cdot 2$ \\
\hline 11 & LGM & IC & Wilt-CP & 63.9 & $114 \cdot 2$ & $57 \cdot 0$ \\
\hline 12 & RMP & IC & Adopt. asses./imp. evl. & - & - & - \\
\hline 13 & RMP & IC & Res. resource. alloc'n & - & - & - \\
\hline 14 & RMP & IC & Soil nutrients & $130 \cdot 3$ & $35 \cdot 9$ & $43 \cdot 4$ \\
\hline 15 & LGM & IC/ISC/SADCC & Early leaf spot-GN & $9 \cdot 1$ & $4 \cdot 4$ & $21 \cdot 3$ \\
\hline 16 & LGM & IC/EARCAL & Genetic poten'l yld-PP & $64 \cdot 0$ & $63 \cdot 5$ & $41 \cdot 5$ \\
\hline 17 & LGM & IC/ISC/SADCC & Yield potential-GN & 29.6 & $12 \cdot 3$ & $23 \cdot 4$ \\
\hline 18 & CRL & IC/WASIP/EARCAL/SADCC & Striga-SG & $78 \cdot 7$ & $41 \cdot 4$ & $46 \cdot 2$ \\
\hline 19 & LGM & IC/ISC/SADCC & Drought-GN & $14 \cdot 5$ & $5 \cdot 2$ & $20 \cdot 3$ \\
\hline 20 & LGM & IC & Root rots-CP & $41 \cdot 3$ & $70 \cdot 3$ & $49 \cdot 1$ \\
\hline 21 & LGM & IC & Bud necrosis virus-GN & $1 \cdot 0$ & $1 \cdot 2$ & 13.9 \\
\hline 22 & CRL & IC/WASIP/SADCC & Grain \& stover yld.-SG & $47 \cdot 1$ & $16 \cdot 6$ & $31 \cdot 7$ \\
\hline 23 & RMP & ISC/WASIP(N) & Soil fertility & $86 \cdot 4$ & $21 \cdot 1$ & $29 \cdot 1$ \\
\hline 24 & LGM & IC & St. mosaic/Fu. wilt-PP & 58.5 & $40 \cdot 4$ & $33 \cdot 5$ \\
\hline 25 & RMP & IC & Soil structure & $29 \cdot 4$ & 5.9 & $22 \cdot 8$ \\
\hline 26 & LGM & IC & Leaf miner-GN & $5 \cdot 7$ & $6 \cdot 0$ & $20 \cdot 8$ \\
\hline 27 & LGM & IC & Biolog. $\mathrm{N}$ fixation-CP & $9 \cdot 6$ & $16 \cdot 6$ & $30 \cdot 4$ \\
\hline 28 & LGM & IC & Leaf miner (MGT)-GN & $4 \cdot 8$ & $4 \cdot 5$ & $21 \cdot 3$ \\
\hline 29 & RMP & IC & Water deficit & $122 \cdot 8$ & $19 \cdot 1$ & $32 \cdot 9$ \\
\hline 30 & LGM & IC & Spodoptera-GN & 0.7 & 0.9 & $13 \cdot 3$ \\
\hline 31 & LGM & IC & Peanut clump virus-GN & $5 \cdot 7$ & $4 \cdot 9$ & $21 \cdot 0$ \\
\hline 32 & LGM & IC/ISC/SADCC & Posette virus-GN & $20 \cdot 8$ & $8 \cdot 6$ & $23 \cdot 1$ \\
\hline 33 & LGM & IC & Helicoverpa (MGT)-PP & $26 \cdot 0$ & $23 \cdot 8$ & $29 \cdot 7$ \\
\hline 34 & CRL & IC/WASIP/EARCAL/SADCC & Stem borer-SG & $8 \cdot 4$ & 1.6 & $16 \cdot 1$ \\
\hline 35 & CRL & IC/WASIP/EARCAL & Grain mold-SG & $66 \cdot 0$ & $21 \cdot 5$ & $32 \cdot 2$ \\
\hline 36 & LGM & ISC & Millipedes-GN & $3 \cdot 0$ & $8 \cdot 0$ & $23 \cdot 8$ \\
\hline 37 & RMP & ISC/WASIP(N) & Water deficit-PM,SG,GN & $22 \cdot 0$ & 3.9 & $19 \cdot 4$ \\
\hline 38 & RMP & ISC/WASIP(M,N) & Tech. adopt./imp/ eval. & - & - & - \\
\hline 39 & RMP & ISC/WASIP & Agroforestry & $16 \cdot 7$ & 3.5 & $17 \cdot 7$ \\
\hline 40 & RMP & ISC/WASIP(N) & Char'n of prod'n envi't & - & - & - \\
\hline 41 & LGM & IC & Nematodes-GN,PP,CP & 151 & $5-9$ & $21 \cdot 3$ \\
\hline 42 & LGM & ISC & Termites-GN & $2 \cdot 3$ & $2 \cdot 4$ & $16 \cdot 7$ \\
\hline 43 & LGM & IC & Suboptimal yield-CP & 0.9 & 0.5 & $12 \cdot 6$ \\
\hline 44 & CRL & EARCAL & Low temperature-SG & 1.6 & $9 \cdot 6$ & 13.4 \\
\hline 45 & LGM & ISC & White grubs-GN & $1 \cdot 3$ & 1.6 & $15-8$ \\
\hline 46 & CRL & IC/WASIP & Head bug-SG & $12 \cdot 8$ & $7 \cdot 1$ & $24 \cdot 7$ \\
\hline 47 & LGM & IC/EARCAL & Drought-PP & $19 \cdot 7$ & $7 \cdot 7$ & $24 \cdot 0$ \\
\hline 48 & CRL & IC.WASIP/EARCAL/SADCC & Anthracnose-SG & $13 \cdot 5$ & $4 \cdot 6$ & $25 \cdot 5$ \\
\hline 49 & CRL & IC.WASIP/EARCAL & Midge-SG & $14 \cdot 4$ & $4 \cdot 1$ & $19 \cdot 4$ \\
\hline 50 & RMP & IC & Char'zation of environ. & - & -- & - \\
\hline 51 & RMP & IC/EARCAL & Microecon studies & - & - & - \\
\hline 52 & RMP & IC & Natural resources & - & - & - \\
\hline 53 & RMP & IC & Supply $\&$ demand & - & - & - \\
\hline 54 & RMP & IC & Farmers' preferences & - & - & - \\
\hline 55 & RMP & IC & Beneficial organisms & $27 \cdot 3$ & $11 \cdot 3$ & $27 \cdot 4$ \\
\hline 56 & RMP & SADCC & Plant nutr'n-SG/PM/FM & $4 \cdot 5$ & $13 \cdot 0$ & $29 \cdot 0$ \\
\hline 57 & I_GM & IC. & Peanut mottle virus-GN & $3 \cdot 9$ & $3 \cdot 5$ & $19 \cdot 6$ \\
\hline
\end{tabular}


TABLE 3

ICRISATs Portfolio of (Ranked) Research Themes-contd.

\begin{tabular}{|c|c|c|c|c|c|c|c|}
\hline \multicolumn{2}{|c|}{ Research cost } & \multicolumn{2}{|c|}{ Equity } & \multirow[b]{2}{*}{$\begin{array}{l}\text { Internationality } \\
\quad(\text { index })\end{array}$} & \multirow[b]{2}{*}{$\begin{array}{l}\text { Sustainability } \\
\text { (index) }\end{array}$} & \multirow[b]{2}{*}{$\begin{array}{l}\text { Composite } \\
\text { index }\end{array}$} & \multirow[b]{2}{*}{$\begin{array}{l}\text { Cumulative } \\
\text { cost (\$mill) }\end{array}$} \\
\hline $\begin{array}{l}\text { Fïrst year } \\
\text { (\$mill) }\end{array}$ & $\begin{array}{c}\text { Average } \\
94-98 \\
\text { (\$mill) }\end{array}$ & $\begin{array}{c}\text { Poverty } \\
\text { (million poor) }\end{array}$ & $\begin{array}{c}\text { Gender } \\
\text { (million fem. ill.) }\end{array}$ & & & & \\
\hline 0.19 & $0 \cdot 13$ & 397.0 & $378 \cdot 0$ & 1.00 & 4 & $5 \cdot 21$ & $0 \cdot 19$ \\
\hline $0 \cdot 14$ & $0 \cdot 12$ & 397.0 & 378.0 & 1.00 & 5 & $4 \cdot 24$ & 0.33 \\
\hline $0 \cdot 48$ & 042 & $60 \cdot 6$ & $119 \cdot 5$ & 0.55 & 3 & 3.64 & 0.81 \\
\hline $0 \cdot 10$ & 0.09 & 397.0 & 378.0 & 1.00 & 3 & 3.63 & 0.91 \\
\hline $0 \cdot 14$ & 0.09 & $9 \cdot 9$ & $74 \cdot 4$ & 0.57 & 1 & $3 \cdot 48$ & $1 \cdot 05$ \\
\hline $0 \cdot 33$ & 0.28 & 337.0 & $310-0$ & 0.70 & 3 & $3 \cdot 35$ & 1.38 \\
\hline $0 \cdot 05$ & 0.04 & $248 \cdot 2$ & $298 \cdot 6$ & 0.82 & 5 & $3 \cdot 28$ & $1 \cdot 43$ \\
\hline 0.43 & 0.36 & $329 \cdot 0$ & $302 \cdot 0$ & 0.84 & 4 & 3.00 & $1 \cdot 86$ \\
\hline 0.56 & 0.47 & $360 \cdot 0$ & 308.0 & 0.60 & 5 & $2 \cdot 96$ & $2 \cdot 42$ \\
\hline $0 \cdot 25$ & $0 \cdot 16$ & $88 \cdot 2$ & $107 \cdot 9$ & $0 \cdot 26$ & 4 & 2.94 & $2 \cdot 67$ \\
\hline $0 \cdot 14$ & 0.09 & $88 \cdot 2$ & $107 \cdot 9$ & 0.26 & 1 & $2 \cdot 90$ & $2 \cdot 81$ \\
\hline 0.62 & 0.52 & $75 \cdot 9$ & $114 \cdot 1$ & 0.00 & 3 & - & 3.43 \\
\hline $0 \cdot 21$ & 0.11 & 397.0 & $378 \cdot 0$ & 1.00 & 4 & - & $3 \cdot 64$ \\
\hline $0 \cdot 54$ & 0.45 & 167.9 & $162 \cdot 2$ & 0.49 & 5 & $2 \cdot 81$ & $4 \cdot 18$ \\
\hline $0 \cdot 45$ & 0.37 & $345 \cdot 0$ & 313.0 & $0 \cdot 70$ & 4 & $2 \cdot 75$ & $4 \cdot 63$ \\
\hline $0 \cdot 13$ & $0 \cdot 11$ & $125 \cdot 2$ & $168 \cdot 2$ & 0.23 & 3 & $2 \cdot 53$ & $4 \cdot 76$ \\
\hline 0.44 & 0.37 & $234 \cdot 2$ & $363 \cdot 4$ & 0.71 & 3 & 2.53 & $5 \cdot 20$ \\
\hline $0 \cdot 28$ & 0.23 & $31 \cdot 5$ & $43 \cdot 8$ & 0.80 & 4 & $2 \cdot 51$ & $5 \cdot 48$ \\
\hline 0.50 & 0.42 & 331.8 & $326 \cdot 0$ & 0.62 & 3 & $2 \cdot 43$ & 5.98 \\
\hline $0 \cdot 14$ & 0.09 & $88 \cdot 2$ & 107.9 & $0 \cdot 33$ & 2 & $2 \cdot 34$ & $6 \cdot 12$ \\
\hline $0 \cdot 13$ & $0 \cdot 11$ & 298.9 & $328 \cdot 1$ & 0.66 & 3 & $2 \cdot 33$ & $6 \cdot 25$ \\
\hline 0.68 & 0.57 & 180.8 & $169 \cdot 2$ & 0.85 & 3 & $2 \cdot 33$ & 6.93 \\
\hline 0.58 & 0.48 & 16.8 & $37 \cdot 9$ & 0.76 & 5 & $2 \cdot 28$ & $7 \cdot 51$ \\
\hline 0.21 & 0.17 & $125 \cdot 2$ & $168 \cdot 2$ & 0.12 & 4 & $2 \cdot 21$ & $7 \cdot 72$ \\
\hline 0.74 & 0.62 & 167.9 & $162 \cdot 2$ & 0.46 & 5 & $2 \cdot 18$ & $8 \cdot 46$ \\
\hline $0 \cdot 19$ & $0 \cdot 16$ & $195 \cdot 7$ & 268.6 & 0.46 & 4 & $2 \cdot 17$ & 8.65 \\
\hline $0 \cdot 10$ & 0.09 & $88 \cdot 2$ & 133.7 & 0.43 & 5 & $2 \cdot 16$ & 8.75 \\
\hline $0 \cdot 23$ & 0.19 & $195 \cdot 7$ & $268 \cdot 6$ & 0.46 & 4 & $2 \cdot 14$ & 8.98 \\
\hline 0.95 & 0.79 & 154.4 & 151.4 & 0.34 & 4 & 2.03 & $9 \cdot 93$ \\
\hline 0.14 & $0 \cdot 12$ & $174 \cdot 7$ & $247 \cdot 6$ & 0.40 & 4 & 1.93 & $10 \cdot 07$ \\
\hline 0.23 & 0.19 & $114 \cdot 3$ & $124 \cdot 0$ & 0.84 & 3 & 1.87 & $10 \cdot 30$ \\
\hline 0.53 & 0.39 & 71.9 & $71 \cdot 4$ & 0.89 & 3 & 1.82 & 10.83 \\
\hline 0.17 & 0.14 & $98 \cdot 2$ & $136 \cdot 4$ & 0.17 & 4 & 1.82 & 11.00 \\
\hline 0.76 & 0.63 & $232 \cdot 7$ & $191 \cdot 2$ & 0.75 & 2 & 1.82 & $11 \cdot 76$ \\
\hline 0.45 & $0 \cdot 38$ & $51 \cdot 2$ & $57 \cdot 2$ & 0.68 & 3 & 1.81 & $12 \cdot 21$ \\
\hline $0 \cdot 04$ & 0.03 & $27 \cdot 3$ & 37.2 & 0.77 & 4 & 1.80 & $12 \cdot 25$ \\
\hline 0.83 & 0.69 & $24 \cdot 1$ & $42 \cdot 6$ & 0.76 & 4 & 1.71 & 13.08 \\
\hline 0.29 & 0.24 & $24 \cdot 1$ & $42 \cdot 6$ & 0.83 & 2 & - & 13.37 \\
\hline 0.60 & 0.55 & $24 \cdot 1$ & $42 \cdot 6$ & 0.76 & 4 & $1 \cdot 70$ & 13.97 \\
\hline 0.72 & $0 \cdot 60$ & $24 \cdot 1$ & $42 \cdot 6$ & 0.76 & 3 & - & 14.69 \\
\hline 0.41 & 0.34 & $179 \cdot 7$ & 263.9 & 0.27 & 3 & 1.69 & $15 \cdot 10$ \\
\hline 0.11 & 0.09 & $27 \cdot 3$ & $37 \cdot 2$ & 0.77 & 4 & 1.68 & $15 \cdot 21$ \\
\hline 0.25 & 0.21 & $88 \cdot 2$ & $133 \cdot 7$ & 0.52 & 4 & 1.68 & $15 \cdot 46$ \\
\hline $0 \cdot 19$ & $0 \cdot 17$ & $32 \cdot 7$ & $11 \cdot 8$ & 0.60 & 4 & 1.63 & 15.65 \\
\hline $0 \cdot 11$ & 0.09 & $27 \cdot 3$ & $37 \cdot 2$ & 0.72 & 4 & $1 \cdot 62$ & $15 \cdot 76$ \\
\hline 0.27 & 0.22 & 43.3 & 74.8 & 0.76 & 3 & 1.61 & 16.03 \\
\hline 0.41 & 0.35 & $98 \cdot 2$ & $136 \cdot 4$ & 0.28 & 4 & 1.61 & 16.44 \\
\hline 0.43 & $0 \cdot 36$ & $126 \cdot 7$ & $110 \cdot 8$ & 0.82 & 2 & 1.60 & 16.87 \\
\hline 0.52 & 0.43 & 56.6 & $47 \cdot 1$ & 0.82 & 3 & 1.59 & $17 \cdot 39$ \\
\hline 0.25 & 0.21 & 75.9 & $114 \cdot 1$ & 0.00 & 3 & $\ldots$ & 17.64 \\
\hline 0.41 & 0.41 & - & - & - & - & - & $18 \cdot 05$ \\
\hline 0.60 & 0.50 & 75.9 & $114 \cdot 1$ & 0.00 & 5 & - & 18.65 \\
\hline 0.21 & 0.17 & 75.9 & $114 \cdot 1$ & 0.00 & 4 & $\ldots$ & 1886 \\
\hline $0 \cdot 14$ & $0 \cdot 12$ & $75 \cdot 9$ & $114 \cdot 1$ & 0.00 & 3 & $\ldots$ & $19 \cdot 00$ \\
\hline 0.41 & 0.34 & $62 \cdot 4$ & 104.9 & 0.27 & 4 & 1.55 & $19 \cdot 41$ \\
\hline 0.08 & 0.07 & $32 \cdot 1$ & $12 \cdot 4$ & 0.70 & 3 & $1 \cdot 54$ & $19 \cdot 49$ \\
\hline 0.21 & 0.18 & 147.3 & 138.7 & 0.91 & 1 & 1.51 & $19 \cdot 70$ \\
\hline
\end{tabular}


TABLE 3

ICRISATs Portfolio of (Ranked) Rezearch Themes-contd.

\begin{tabular}{|c|c|c|c|c|c|c|}
\hline \multirow[t]{2}{*}{ Rank } & \multirow{2}{*}{$\begin{array}{l}\text { Pro- } \\
\text { gram }\end{array}$} & \multirow[t]{2}{*}{ Center(s)/location(s) } & \multirow[t]{2}{*}{ Constraint/theme } & \multicolumn{3}{|c|}{ Efficiency } \\
\hline & & & & $\begin{array}{c}N P V \\
(\$ m i l)\end{array}$ & $\begin{array}{c}\text { Net } \\
B / C \\
\text { (ratio) }\end{array}$ & $\begin{array}{l}I R R \\
(\%)\end{array}$ \\
\hline \multicolumn{7}{|c|}{ Core funding-contd } \\
\hline 58 & RMP & ISC/WASIP(M) & Cons./demand studies & - & - & - \\
\hline 59 & CRL & IC/ISC/EARCAL/SADCC & Drought-PM & $33 \cdot 7$ & $8 \cdot 9$ & $26 \cdot 6$ \\
\hline 60 & GIP & SADCC & Adaptability-GN & $20 \cdot 0$ & 33.9 & 38.4 \\
\hline 61 & CRL & LASIP & Adapt. to acid soil-SG & $11 \cdot 5$ & $9 \cdot 1$ & $29 \cdot 1$ \\
\hline 62 & LGM & IC & Peanut stripe virus-GN & $4 \cdot 5$ & $4 \cdot 3$ & $20 \cdot 7$ \\
\hline 63 & RMP & SADCC & Drought-SG/PM/FM & 4.9 & $8 \cdot 1$ & $25 \cdot 1$ \\
\hline 64 & CRL & IC/ISC/EARCAL/SADCC & Downy mildew-PM & $75 \cdot 2$ & $16-8$ & $34 \cdot 8$ \\
\hline 65 & CRL & IC/WASIP/EARCAL/SADCC & Drought-SG & $30 \cdot 3$ & $8 \cdot 6$ & $28 \cdot 8$ \\
\hline 66 & CRL & IC/EARCAL/SADCC & Leaf blight-SG & $9 \cdot 6$ & $5 \cdot 0$ & $14 \cdot 2$ \\
\hline 67 & CRL & EÁRCAL & Blast disease-FM & 3.8 & $13 \cdot 8$ & $15 \cdot 0$ \\
\hline 68 & CRl & ISC & Striga-PM & $10 \cdot 7$ & $4 \cdot 8$ & $22 \cdot 4$ \\
\hline 69 & CRL & IC/ISC & Low grain yld-PM & $59 \cdot 4$ & $10-5$ & $40 \cdot 0$ \\
\hline 70 & LGM & IC & Phyto.blight (MGT)-PP & $9 \cdot 2$ & 15.9 & $33 \cdot 2$ \\
\hline 71 & LGM & IC & Helicoverpa-PP & 1.8 & 0.8 & 12.9 \\
\hline 72 & CRL & LASIP & Foliar disease res.-SG & $5 \cdot 8$ & $3 \cdot 3$ & $20 \cdot 0$ \\
\hline 73 & SMIP & SADCC & Impr. of grain yield-FM & $4 \cdot 0$ & $5 \cdot 6$ & $22 \cdot 0$ \\
\hline 74 & $\mathrm{ECO}$ & SADCC & Res. impact-SG/PM/FM & - & - & - \\
\hline 75 & ECO & SADCC & Policy a'lysis-SG/PM/FM & - & - & - \\
\hline 76 & CRL & IC & Shoot fly-SG & $22 \cdot 5$ & $12 \cdot 4$ & $26 \cdot 2$ \\
\hline 77 & CRL & IC & Lack of adapt. (arid)-PM & $12 \cdot 5$ & 9.9 & $38 \cdot 3$ \\
\hline 78 & LGM & IC & Maruca-PP & 0.7 & 1.9 & $15 \cdot 4$ \\
\hline 79 & LGM & IC & Stunt virus-CP & 0.8 & $1 \cdot 1$ & $14 \cdot 4$ \\
\hline 80 & LGM & IC/EARCAL & Podfly (MGT)-PP & $7 \cdot 5$ & $8 \cdot 0$ & $23 \cdot 3$ \\
\hline 81 & LGM & IC & Water logging-PP & $12 \cdot 6$ & 7.0 & $23 \cdot 4$ \\
\hline 82 & LGM & IC/EARCAL & Podfly-PP & 0.5 & 0.5 & $12 \cdot 0$ \\
\hline 83 & CRL & IC/ISC & Head catepillars-PM & $8 \cdot 0$ & 4-0 & $22 \cdot 3$ \\
\hline 84 & CRL & IC/ISC & High temperature-PM & $15 \cdot 5$ & 5.9 & $25 \cdot 8$ \\
\hline 85 & LGM & $\mathrm{IC}$ & Cold tolerance-CP & $9 \cdot 2$ & $7 \cdot 6$ & $25 \cdot 1$ \\
\hline 86 & CRL & IC/SADCC & Forage sorghum-SG & $12 \cdot 2$ & 9.9 & $39 \cdot 2$ \\
\hline 87 & CRL & IC/ISC & Stem borers-PM & $2 \cdot 1$ & $1 \cdot 1$ & $15 \cdot 1$ \\
\hline 88 & LGM & IC & Botrytis gray mold-CP & 2.7 & $2 \cdot 9$ & $18 \cdot 3$ \\
\hline 89 & ECO & SADCC & Seed d'bution-SG/PM/FM & - & - & - \\
\hline 90 & ECO & SADCC & Market reform-SG/PM/FM & - & - & \\
\hline 91 & RMP & IC & Inst'l \& human res'rces & - & $\ldots$ & - \\
\hline 92 & RMP & IC & Input markets & - & - & - \\
\hline \multicolumn{7}{|c|}{ Complementary funding } \\
\hline 93 & $\mathrm{CQU}$ & IC/SADCC/EARCAL/WASIP & Quality/Utilization-SG & $28 \cdot 0$ & 36.9 & $36 \cdot 8$ \\
\hline 94 & RMP & ISC/WASIP & Weeds & $14 \cdot 6$ & $6 \cdot 5$ & $21 \cdot 7$ \\
\hline 95 & RMP & SADCC & Weed (MGT)-SG,PM,FM & $8 \cdot 6$ & $10 \cdot 0$ & $26 \cdot 7$ \\
\hline 96 & CRL & LASIP & Acid soil adaplion-SG & $11 \cdot 5$ & $9 \cdot 1$ & $29 \cdot 1$ \\
\hline 97 & LGM & ISC & Aphids-GN & 0.2 & $0 \cdot 1$ & $13 \cdot 1$ \\
\hline 98 & RMP & SADCC & Nematodes-SG & 0.8 & $2 \cdot 2$ & $17 \cdot 5$ \\
\hline 99 & LGM & EARCAL/MALAWI & Crop improvement-PP & $7 \cdot 6$ & $2 \cdot 2$ & $18 \cdot 7$ \\
\hline 100 & CRL & SADCC/WASIP & Sooty stripe-SG & 0.2 & 0.2 & $11-1$ \\
\hline 101 & CRL & WASIP/EARCAL & Long smut-SG & $5 \cdot 5$ & $4 \cdot 7$ & $20 \cdot 5$ \\
\hline 102 & SMIP & SADCC & Storage pests-SG,PM & 0.0 & $0 \cdot 1$ & $9 \cdot 5$ \\
\hline 103 & CRL & ISC & Low grain yield-PM & 6.7 & $5 \cdot 5$ & $25 \cdot 0$ \\
\hline 104 & SMIP & SADCC & Ergot-SG & 1.9 & $4 \cdot 0$ & $25 \cdot 0$ \\
\hline 105 & GIP & SADCC & Imp. c'vars confec.-GN & $7 \cdot 5$ & $8 \cdot 2$ & $25 \cdot 1$ \\
\hline 106 & SMIP & SADCC & Photosensitive-PM & 1.0 & $3 \cdot 0$ & $17 \cdot 2$ \\
\hline 107 & SMIP & SADCC & Photosensitive-SG & 0.3 & 3.9 & $20 \cdot 0$ \\
\hline 108 & CQU & SADCC & Qlty. scre'ing SG/PM/FM & & & \\
\hline 109 & CQU & SADCC & A'lty imp'ment-SG/PM/FM & - & - & - \\
\hline 110 & CQU & SADCC & Sweet stem sorghum-SG & - & - & - \\
\hline
\end{tabular}


TABLE 3

ICRISATs Portfolio of (Ranked) Research Themes-contd.

\begin{tabular}{|c|c|c|c|c|c|c|c|}
\hline \multicolumn{2}{|c|}{ Research cost } & \multicolumn{2}{|c|}{ Equity } & \multirow[b]{2}{*}{$\begin{array}{l}\text { Internationality } \\
\quad(\text { index })\end{array}$} & \multirow[b]{2}{*}{$\begin{array}{l}\text { Sustainability } \\
\text { (index) }\end{array}$} & \multirow[b]{2}{*}{$\begin{array}{l}\text { Composite } \\
\text { index }\end{array}$} & \multirow[b]{2}{*}{$\begin{array}{l}\text { Cumulative } \\
\text { cost (\$mill) }\end{array}$} \\
\hline $\begin{array}{l}\text { First year } \\
\text { (Smill) }\end{array}$ & $\begin{array}{c}\text { Average } \\
94-98 \\
(8 \mathrm{mill})\end{array}$ & $\begin{array}{c}\text { Poverty } \\
\text { (million poor) }\end{array}$ & $\begin{array}{c}\text { Gender } \\
\text { (million fem. ill.) }\end{array}$ & & & & \\
\hline 0.21 & 0.17 & $24 \cdot 1$ & $42 \cdot 6$ & 0.78 & 2 & - & $19 \cdot 91$ \\
\hline 0.56 & 0.47 & $65 \cdot 3$ & 116.7 & 0.48 & 3 & 1.48 & $20 \cdot 47$ \\
\hline 0.08 & 0.07 & 12.9 & $12 \cdot 4$ & 0.75 & 1 & 1.47 & $20 \cdot 55$ \\
\hline $0 \cdot 19$ & $0 \cdot 19$ & 48.9 & $20 \cdot 5$ & 0.64 & 3 & 1.45 & $20 \cdot 74$ \\
\hline $0 \cdot 18$ & $0 \cdot 15$ & $97 \cdot 1$ & $47 \cdot 1$ & 0.54 & 3 & 1.40 & $20 \cdot 92$ \\
\hline $0 \cdot 14$ & $0 \cdot 12$ & $32 \cdot 1$ & $12 \cdot 4$ & 0.65 & 3 & 1.40 & $21 \cdot 06$ \\
\hline $1 \cdot 12$ & 0.89 & $64 \cdot 1$ & 114.6 & 0.23 & 3 & 1.39 & $22 \cdot 18$ \\
\hline 0.85 & 0.71 & $31 \cdot 4$ & $229 \cdot 7$ & 0.76 & 1 & $1 \cdot 38$ & 23.03 \\
\hline 0.33 & 0.28 & $37 \cdot 4$ & $52 \cdot 0$ & 0.86 & 2 & $1 \cdot 37$ & $23 \cdot 36$ \\
\hline 0.33 & 0.29 & $60 \cdot 0$ & $23 \cdot 1$ & 0.68 & 2 & $1 \cdot 36$ & 23.69 \\
\hline 0.33 & 0.28 & $10 \cdot 7$ & $31 \cdot 1$ & 0.66 & 3 & $1 \cdot 33$ & $24 \cdot 02$ \\
\hline 0.87 & 0.71 & 55.4 & $93 \cdot 6$ & $0 \cdot 32$ & 3 & $1 \cdot 30$ & 24.89 \\
\hline $0 \cdot 12$ & 0.09 & 103.9 & $147 \cdot 4$ & 0.01 & 3 & 1.28 & $25 \cdot 01$ \\
\hline 0.32 & 0.27 & $98 \cdot 2$ & 136.4 & 0.08 & 4 & 1.27 & 25.33 \\
\hline 0.41 & 0.41 & 71.9 & $23 \cdot 3$ & 0.50 & 3 & $1 \cdot 25$ & $25 \cdot 74$ \\
\hline 0.21 & 0.14 & $13 \cdot 1$ & 6.8 & 0.55 & 3 & $1 \cdot 20$ & 25.95 \\
\hline 0.12 & 0.07 & 11.9 & $4 \cdot 6$ & 0.48 & 1 & - & 26.07 \\
\hline $0 \cdot 12$ & $0 \cdot 10$ & $85 \cdot 7$ & $34 \cdot 4$ & 0.76 & 1 & 一 & $26 \cdot 19$ \\
\hline 0.27 & 0.22 & $45 \cdot 6$ & $67 \cdot 3$ & 0.49 & 2 & $1 \cdot 19$ & $26 \cdot 46$ \\
\hline 0.66 & 0.25 & $20 \cdot 5$ & $68 \cdot 7$ & 0.33 & 3 & $1 \cdot 18$ & $27 \cdot 12$ \\
\hline 0.06 & 0.05 & $52 \cdot 5$ & $102 \cdot 4$ & 0.11 & 4 & $1 \cdot 17$ & $27 \cdot 18$ \\
\hline $0 \cdot 10$ & 0.09 & $88 \cdot 2$ & $107 \cdot 9$ & 0.25 & 3 & $1 \cdot 13$ & $27 \cdot 28$ \\
\hline $0 \cdot 14$ & 0.12 & $70 \cdot 4$ & 130.0 & 0.08 & 3 & $1 \cdot 10$ & $27 \cdot 42$ \\
\hline $0 \cdot 30$ & 0.25 & 89.4 & $125 \cdot 7$ & 0.05 & 3 & 1.08 & $27 \cdot 72$ \\
\hline 0.14 & 0.12 & $70 \cdot 4$ & $130 \cdot 0$ & $0 \cdot 20$ & 3 & 1.07 & $27 \cdot 86$ \\
\hline $0 \cdot 30$ & 0.25 & $10 \cdot 3$ & $27 \cdot 5$ & 0.59 & 2 & 0.99 & $28 \cdot 16$ \\
\hline 0.50 & 0.41 & $58 \cdot 8$ & 113.6 & 0.29 & 2 & 0.96 & $28 \cdot 66$ \\
\hline 0.23 & 0.21 & $20 \cdot 2$ & $66 \cdot 1$ & 0.03 & 3 & $0 \cdot 83$ & 28.89 \\
\hline $0 \cdot 25$ & $0 \cdot 19$ & $84 \cdot 2$ & $72 \cdot 3$ & $0 \cdot 28$ & 1 & 0.77 & $29 \cdot 14$ \\
\hline 0.29 & 0.24 & $2 \cdot 5$ & $23 \cdot 8$ & 0.44 & 2 & 0.76 & $29 \cdot 43$ \\
\hline $0 \cdot 19$ & $0 \cdot 16$ & $30 \cdot 1$ & $82 \cdot 8$ & 0.48 & 1 & 0.74 & $29 \cdot 62$ \\
\hline 0.19 & $0 \cdot 10$ & $14 \cdot 8$ & $5 \cdot 5$ & 0.65 & 2 & - & 29.81 \\
\hline $0 \cdot 17$ & $0 \cdot 11$ & $20 \cdot 5$ & $10 \cdot 5$ & 0.72 & 1 & - & $29 \cdot 98$ \\
\hline $0 \cdot 12$ & $0 \cdot 10$ & 75.9 & $114 \cdot 1$ & 0.00 & 4 & 一 & $30 \cdot 10$ \\
\hline 008 & 0.06 & 759 & $114 \cdot 1$ & 0.00 & 2 & - & 3018 \\
\hline 0.13 & $0 \cdot 11$ & $185 \cdot 7$ & $169 \cdot 2$ & 0.79 & 3 & $2 \cdot 68$ & $30 \cdot 31$ \\
\hline $0 \cdot 33$ & $0 \cdot 28$ & $24 \cdot 1$ & $42 \cdot 6$ & 0.76 & 3 & 1.51 & $30 \cdot 64$ \\
\hline 0.21 & 0.17 & $32 \cdot 1$ & $12 \cdot 4$ & 0.72 & 3 & 1.50 & $30 \cdot 85$ \\
\hline 0.23 & $0 \cdot 19$ & $48 \cdot 9$ & $20 \cdot 5$ & 0.69 & 3 & 1.45 & $31 \cdot 08$ \\
\hline $0 \cdot 18$ & $0 \cdot 15$ & $27 \cdot 3$ & $37 \cdot 2$ & 0.77 & 3 & $1 \cdot 39$ & $31 \cdot 26$ \\
\hline 0.09 & 0.08 & 5.8 & $1 \cdot 6$ & 0.53 & 4 & 1.34 & $31 \cdot 35$ \\
\hline 0.83 & 0.69 & $23 \cdot 0$ & 14.5 & 0.73 & 3 & 1.34 & $32 \cdot 17$ \\
\hline 0.17 & $0 \cdot 14$ & 22.9 & $40 \cdot 6$ & 0.78 & 2 & $1 \cdot 15$ & $32 \cdot 34$ \\
\hline 0.17 & $0 \cdot 14$ & 4.4 & 7.9 & 0.71 & 2 & 1.08 & $32 \cdot 51$ \\
\hline 0.12 & $0 \cdot 10$ & $17 \cdot 3$ & $9 \cdot 7$ & 0.48 & 3 & 1.03 & 32.63 \\
\hline 0.21 & $0 \cdot 16$ & $11 \cdot 5$ & $29 \cdot 6$ & 0.32 & 3 & 1.00 & $32 \cdot 84$ \\
\hline $0 \cdot 18$ & $0 \cdot 10$ & $13 \cdot 7$ & $5 \cdot 5$ & 0.68 & 1 & 0.80 & 33.02 \\
\hline 0.17 & $0 \cdot 14$ & 3.9 & $3 \cdot 0$ & 0.55 & 1 & 0.73 & $33 \cdot 19$ \\
\hline 0.08 & 0.07 & $2 \cdot 0$ & $3 \cdot 8$ & 0.00 & 3 & 0.57 & $33 \cdot 27$ \\
\hline 0.02 & 0.01 & 3.6 & $3 \cdot 8$ & $0 \cdot 30$ & 1 & 0.39 & $33 \cdot 29$ \\
\hline 0.17 & 0.14 & $17 \cdot 3$ & $7 \cdot 1$ & 0.54 & 1 & - & 33.46 \\
\hline 0.05 & 0.04 & $17 \cdot 3$ & $7 \cdot 1$ & 0.54 & 3 & - & $33 \cdot 51$ \\
\hline 0.14 & 0.12 & 15.9 & 6.9 & 0.44 & 4 & - & 33.85 \\
\hline
\end{tabular}

GRU (Genetic Resources Unit), LGM (Legumes Program), RMP (Resource Management Program), CRL (Cereals Program), GIP (Groundnut Improvement Program), ECO (Economics), CQU (Crop Quality Unit), SMIP (Sorghum \& Millet Program).

CP (Chickpea), GN (Groundnut), PP (Pigeonpea), PM (Pearl Millet), SG (Sorghum), FM (Finger Millet).

MGT (Management). 


\section{Participation}

ICRISAT's MTP 1994-98 represents the culmination of months of institute-level meetings, seminars and management committee deliberations. The broadest possible representation was sought in developing a plan which would define the organization's research agenda for the plan period. With an 11-member Working Group, a good balance was achieved between broad representation and time limits: a larger number might have jeopardized the 'brainstorming', inhibited discussion, and tied up more of valuable scientists' time. Yet each group within ICRISAT had a representative to interface with the Working Group. The ongoing process of discussion and information gathering on all levels created an atmosphere of openness and participation so that 'at the end of this process, though debate continued about specific data points, most scientists in the Institute identified the Medium Term Plan with a sense of ownership' (Rohrbach, 1993: p. 3). Improved cross-disciplinary and cross-location linkages remain as long-term benefits.

\section{Effects on resource allocation}

Figure 5 shows the distribution of core funds across programs and crops at the proposed funding level of $\$ 30.2$ million and at $\$ 27.5$ million, respectively, in comparison to the proportions relating to ICRISAT's 1992 budget allocation. Groundnuts (Legumes Program (LGMP)) and the Resource Management Program (RMP), particularly the Economics Group, are the crops and programs where a strengthening (sizing up) of research activity is envisioned, chickpea and pigeonpea remain relatively constant. Funding levels and corresponding research activity in the sorghum and millet groups (Cereals Program) are projected to decline, particularly under the low budget plan. Increased emphasis on resource management research reflects the high priority accorded themes focusing on long-term productivity potential, i.e. upgrading the resource base. Groundnut themes generally rank high because of their comparatively higher market price and their wide distribution throughout the world.

\section{Inherent bias}

Obviously, the 'evaluation' of research themes and the resulting institutional adjustments will raise concerns among scientists. The question of 'bias' arises. Are the estimates of yield improvement by the various programs and locations realistic? Are the time frames reasonable? Which are the appropriate prices to use? Are scientists' years estimated realistically? 
(a)

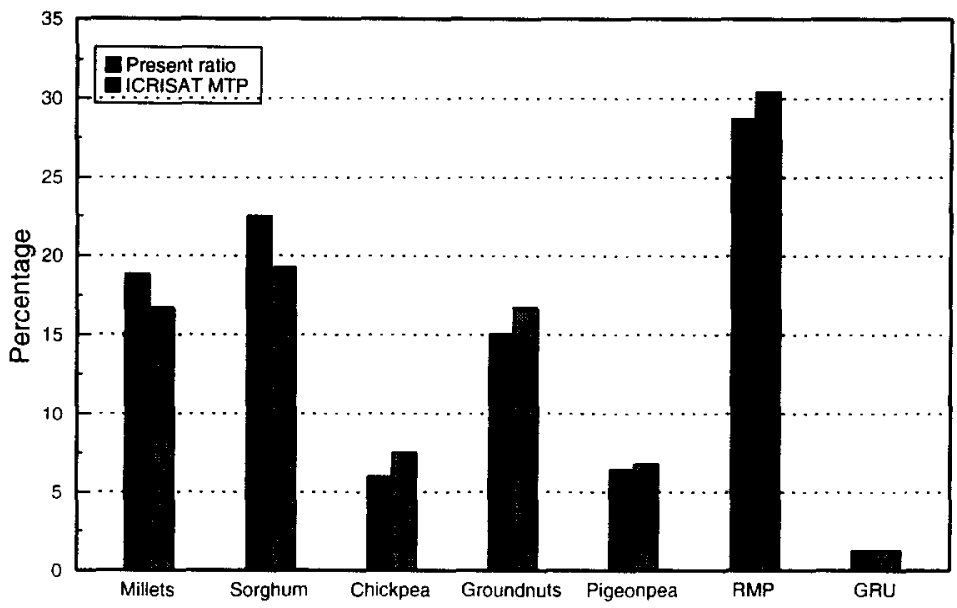

(b)

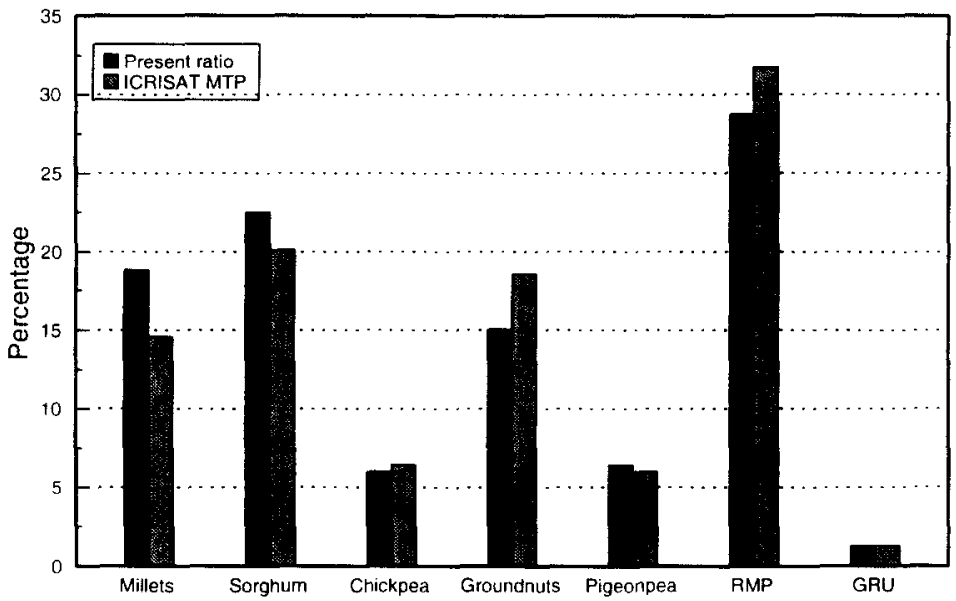

Fig. 5. Distribution of core funds at proposed level of (a) $\$ 30.18$ million and (b) $\$ 27.42$ million.

Questions about the reliability of information generated through this process and the inherent bias are legitimate. It should be recognized that individual scientists may be induced to exaggerate - by inflating estimates of expected yield improvements from research or by underestimating staff requirements and research lags - since these factors will have a pronounced effect on the net benefit-cost ratio. This is a phenomenon known as 'moral hazard' (Just et al., 1982). While moral hazards do exist (which allows for potential bias to creep in), the decision to base the evaluation on scientists' own judgements and estimates can still be a sound one, especially when considering the following: 
(1) Scientists themselves are reasonably good judges (perhaps the best) of the potential contribution of their research and thus are probably better positioned than anyone else to specify likely research lags, probabilities of success, staff requirements, and expected yield improvements from their own research. An alternative would be 'outside expert opinion'. While this was done to verify estimates of yield losses from the various constraints by consulting NARS, time limitations and the difficulty in realistically assessing the potentials and probabilities of such a broad range of research activities at such an institute did not allow it for other parameters.

(2) With a first-time exercise, the full implications of the impact of scientists' estimates on the priority setting process is probably not yet fully appreciated. The fact that their own research themes are competing with others', if indeed scientists are conscious of this predicament in the early stages when much of the yield loss and gain data are collected, does not appear to produce conscious over-/under-estimation of figures.

(3) Estimates are generated among groups of scientists in related disciplines before being passed on to the coordinating body. Later, themes are presented at seminars in which scientists defend those estimates. There are numerous opportunities for peer review and several layers of scrutiny and review before the research protocols are finalized. Often figures are re-estimated in the light of evidence based on on-station and on-farm research results.

(4) Ultimately, research directors must sign off on their program's themes and the contents, which are presented and discussed in detail in senior management meetings. To avoid intentional 'fudging' of numbers, it should be made clear to scientists that the parameters used in deriving the efficiency measures will be used as milestones in monitoring and evaluation of research on the themes. Eventually, sensitivity analysis can be carried out to determine how variable the distributions of key parameters are between programs and crops (Bantilan, 1994). In general, sensitivity analysis reaffirmed the robustness of the priority ranking to changes in the estimated parameters.

\section{CONCLUSIONS}

This paper describes an ex-ante multi-objective framework (economic efficiency, equity, internationality and sustainability) for assessing research priorities at an international agricultural research center. It represents a 
step forward in formulating research agendas as the methodology used provides the supply side orientation missing in the TAC/CGIAR model of Gryseels et al. (1992). The distinct advantage of the framework described is that at a time of intense competition for scarce funds, it makes explicit the benefits that would flow from additional investments to an institute as well as the opportunity costs corresponding to specific reductions in research funds. This kind of information is useful for the TAC and the CGIAR Secretariat making decisions about allocating scarce research resources across CGIAR centers, particularly if the "equi-marginal principle' is to be preserved. ${ }^{19}$

Another advantage of the supply-side approach is the generation of milestones by which research outputs can be evaluated ex-post (McCalla \& Ryan, 1992). Assumptions about yield increases, research lags, probabilities of success and adoption ceilings can be tested against actual delivery of a new research-induced technology. This forms an integral part of the research evaluation process and facilitates revising priorities in the light of such experiences. Admittedly, the basis for the estimates and their assumptions can and will be challenged, ${ }^{20}$ but the value here is in the transparency of the method and the benchmark data that can inform discussions and decisions.

Two fundamental criticisms in using this 'elaborate' priority-setting approach are the time and costs involved and the degree of scientific subjectivity incorporated. The latter point has been dealt with in the discussion on bias. While it is true that many of the judgements made in the process are subjective, the use of a more transparent, participatory and iterative approach facilitates greater dialogue and clarity of thought and hence ensures a better opportunity for bringing objectivity into the picture. Research priority decisions in the past were at least as subjective. This is a step forward in objectivity in explicitly defining the basis (which can be subsequently argued for and against) for priority assessments. It also encourages biological scientists to view their research in the light of societal goals and thus becomes a built-in 'correction' of any self-serving projects.

As to the former point, there is no question that such an exercise requires a significant - critics would say excessive - amount of data and therefore involves large amounts of scientists' time. But the investment is justified as research managers increasingly rely on research staff to provide the analyses and information necessary to make informed decisions about research plans and strategies to justify 'core' and special project funding. ${ }^{21}$ Enhanced emphasis and spending on research planning should be balanced against the cost of making wrong decisions about basic strategies and priorities. Given the historically high rates of return to agricultural 
research - internal rates of return between 30-70\% (Ruttan, 1982; Norton \& Ortiz, 1992) - the value of information which results in further research investment (and better targeted research) can be quite high. At the institutional and personal level, ICRISAT believes that in developing and implementing a more rigorous and more transparent method, it has wisely invested its scientists' time and expertise. With confidence, the Institute - managers as well as scientists - is well positioned to assess its priorities from the perspective of maximizing the benefit streams to target groups. It also has a solid base for becoming ever more responsive to donors' needs for accountability as the extensive 'reference' database and database-modeling system put into place through the MTP exercise facilitate subsequent analyses and evaluations of many kinds.

\section{ACKNOWLEDGEMENTS}

In one way or another all ICRISAT scientists and many of the supporting research and administrative staff participated in the development of the 1994-98 MTP, a truly institute-wide effort. However, the authors want to especially acknowledge the extensive contributions of other members of the MTP Working Group: R. P. Ariyanayagam, C. T. Hash, C. Johansen, S. N. Nigam, C. Renard, D. D. Rohrbach, O. Singh, J. W. Stenhouse, H. A. van Rheenen and S. M. Virmani. Without the support of the Economics Group Staff, in particular M. Asokan, K. V. Subba Rao, P. Parthasarathy Rao, R. Hariharan, S. Lalitha and Ch. Vijayakumar, this work could not have been accomplished. A special word of thanks to Hannelore Grisko-Kelley for editorial assistance and useful comments on earlier drafts. R. P. Eaglesfield offered many helpful suggestions as well.

\section{NOTES}

1. Davis et al. (1987) is an example of the supply-side approach wherein ex-ante measures of the relative economic benefits of alternative commodity and regional research portfolios are developed. They too rely chiefly on the congruence method in estimating the equivalent yield increases required in various commodities to equilibrate with the commodity having the largest current value of production; but they do include proxies for probabilities of success, spillovers, adoption lags, etc. in an attempt to incorporate 'supply-side' considerations.

2. For a review of some of the formal models used in research resource allocation and some empirical examples refer to Araji et al. (1978), 
Shumway (1980), Norton and Davis (1981), Ruttan (1982), Fox (1987), Antony and Anderson (1991) and Dagg (1992).

3. For example, crop yield losses per constraint estimated in the first instance by ICRISAT scientists were sent out to 30 NARS in Asia and Africa requesting feedback, i.e. modification or confirmation. Figures provided by the NARS were used whenever differences in estimates occurred.

4. For the net benefit-cost ratio and the number of poor and number of female illiterates, the highest figures were considered too large for normalizing. Instead, a value of 50 was used to normalize the net benefit cost ratios (versus a high of 135), 250,000 for number of poor (vcrsus a high of 397,000) and 300,000 for femalc illiterates (versus a high of 378,000 ). Using a slightly lower figure - a figure determined to be the largest value other than for extremes - at which to normalize had the advantage of allowing greater differentiation between themes at the mid-to-lower end of the distribution. It should be noted that the value chosen by which to normalize affects the spread of normalized values for that criteria, which in turn has an influence on the final index score.

5. A multiplicative model can also be considered, i.e., $\mathrm{CI}_{i}=X_{1 i} * X_{2 i} *$ $X_{3} \mathrm{i} * X_{4 i}$. Compared to the additive model, it significantly penalizes any theme which has a very low value in any of the $X$ s. It is useful in situations when some minimum level of impact for each criterion must be achieved.

6. The country was the basic unit considered in this study and scientists were asked to estimate an average annual yield loss over a 10-year period for the country as a whole, weighted appropriately. Where possible, estimates were given at a more disaggregated level, i.e. for a state or region within the country.

7. See Davis and Ryan (1988) and Bantilan and Davis (1991a) for a discussion and theoretical analysis of spillover effects.

8. There was one exception. Net benefit-cost ratios were not calculated for economics research themes, primarily because of the difficulty of realistically valuing information, the main product of such research (Lindner, 1987). The value of economics research information is the value of the change in decision behavior (of the scientist, research manager or government policy maker) caused by the new information less the cost of that information. In view of the difficulty in attempting to estimate this value, economics research themes were ranked by judgement relative to themes which were valued.

9. This is the most tangible and the most commonly measured economic benefit of agricultural research. However, others such as loss avoidance 
and improvement in crop quality may be equally important. Valuing an output such as quality improvement is more problematic but with some assumptions about the potential for substitution in new uses, benefit measurement can be made.

10. In the absence of reliable data about likely future prices, current world market prices can be used. Future prices, suitably discounted, are the correct measure of value. Also, the use of current world market prices to estimate the expected value of the additional product realized from successful research [in the absence of regional supply and demand elasticities to estimate specific benefits to consumers (through supply shifts and corresponding price declines) and producers (through increased returns per unit cost of production)], is an approximation at best.

11. Transport costs and distortions to prices from subsidies, tariffs, quotas or taxes can, if feasible, be considered here.

12. Some argue that the use of research investment to achieve income redistribution objectives can be a blunt policy instrument. See Ryan and Davis (1988).

13. This does not take into account the possibility of labor migration of poor people to reap rewards from growth in other regions. As David and Otsuka (1993) have shown, these can be significant.

14. Hence the need for a measure of the poverty gap - the distance between the average poor person's means and the cut-off line (Sen, 1979). Foster et al. (1984) took this even further in developing a poverty measure which gave more weight to the poorest individual. See Minhas et al. (1991) and the World Bank $(1990,1992)$ on different measurements of poverty. For ease of interpretation, and because there appears to be a strong correlation between each of these measures (Datt \& Ravillion, 1990), the headcount index of poverty is used in this paper.

15. Adult illiteracy is defined as the proportion of the population over the age of 15 who cannot, with understanding, read and write a short, simple statement on their everyday life.

16. Preliminary scores were given by members of the Working Group, which were reviewed and revised after discussions in seminars and meetings. The final scores were reviewed and approved by the Management Committee.

17. Raising yields in itself, i.e. lowering per unit production costs, implicitly enhances the sustainability of the system by increasing the productivity of limited resources such as land and water, thereby enhancing the economic viability of the cropping system. This is a necessary but not sufficient condition for sustainable agriculture. All 
research themes have a sustainable component in this limited sense. One must look for aspects (positive externalities) which go beyond, having a favorable impact on the environment, human health, or logterm productivity.

18. Data readily available, however, seemed extremely incongruous, and thus the variable was dropped from the analysis.

19. The equi-marginal principle ensures efficient allocation of resources such that the last unit of investment across different activities (institutes) yields a roughly similar product value, however measured.

20. Such challenges are healthy: more interaction among scientists and institutes provides better and more reliable information, thereby sharpening focus and improving decision making.

21. Economists, among others, are frequently called upon to provide substantive inputs into the IARCs' strategic and medium term plans, not only at ICRISAT but at sister centers too (e.g. Centro Internacional de Agricultura Tropical (CIAT), CIMMYT). The research by Mueller (1990) on institute priority setting and decision making substantiates this perception, as does the recent recruitment of an assessment economist at ICRISAT. For a discussion of the economist's comparative advantage in contributing to decision making see Kelley (1992).

\section{REFERENCES}

Antony, G. \& Anderson, J. R. (1991). Modeling technology replacement over time for ex-ante analysis of agricultural research projects. Agricultural Systems, 37, 183-92.

Araji, A. A., Sim, R. J. \& Gardner, R. L. (1978). Returns to agricultural research and extension programs: an ex-ante approach. American Journal of Agricultural Economics (December) 964-8.

Bantilan, M. C. S. (1994). Sensitivity analysis in research priority setting in a multi-objective framework. Paper presented at the 37th Conference of the Australian Agricultural Economics Society, Wcllington, New Zealand, February 1994.

Bantilan, M. C. \& Davis, J. (1991a). Across-commodity spillover effects of research and opportunity costs in a multi-product production environment. Philippine Country Study. ACIAR/ISNAR Project Paper No. 30, February 1991.

Broca, S. A. \& Oram, P. (1991). Study on the location of the poor. Paper prepared for the Standing Committee for Priorities and Strategies of TAC/ CGIAR. IFPRI, Washington, DC.

Byerlee, D., Collinson, M. P., Perrin, R. K., Winkelmann, D. L., Biggs, S., Moscardi, E. R., Martinez, J. C., Harrington, L. \& Benjamin, A. (1980). Planning technologies appropriate to farmers: concepts and procedures. CIMMYT, El Baton, Mexico. 
Cochrane, S. (1980). The effects of education on health. Staff Working Paper No. 405, World Bank, Washington, DC.

Cummings, Jr, R. W. (1992). CGIAR agricultural research priorities. Draft mimeo, August 12, 1992.

Dagg, M. (1992). Research program formulation. Paper presented at the International Seminar on Management of Agricultural Research. Beijing Agricultural University, Beijing, China, 25-27 May 1992.

Datt, G. \& Ravillion, M. (1990). Regional disparities, targeting, and poverty in India. Policy, Research and External Affairs Working Papers (WPS 375). The World Bank, March 1990.

David, C. C. \& Otsuka, K. (1993). Modern Rice Technology and Income Distribution in Asia. Lynne Rienner Publishers, Inc., Boulder, Colorado, USA, 475 pp.

Davis, J., Oram, P. \& Ryan, J. (1987). Assessment of Agricultural Research Priorities: An International Perspective. ACIAR Monograph No 4. Australian Centre for International Agricultural Research, Canberra.

Davis, J. S. \& Ryan, J. G. (1988). Research priorities for ACIAR and information to assist decision making. ACIAR/ISNAR Project Paper No. 11, October 1988.

Ehui, S. K. \& Spencer, D. S. C. (1990). Indices for measuring the sustainability and economic viability of farming systems. RCMP Research Monograph No. 3, Resource and Crop Management Program, IITA.

Evenson, R. E. (1992). Notes on the measurement of the economic consequences of agricultural research investments. In Assessing the impact of international agricultural research for sustainable development. Proceedings from a symposium at Cornell University, Ithaca, NY, USA, 16-19 June 1991, eds D. R. Lee, S. Kearl \& N. Uphoff, 1992.

Ezekiel, H. (1989). Medium term estimates of demand-based food aid requirements and their availability. In Food Aid Projections for the Decade of the 1990s. National Academy Press, Reprint No. 177. International Food Policy Research Institute, Washington, DC.

FAO (1978-81). Reports of the Agro-ecological Zones Project. World Soil Resources Report No. 48. FAO, Rome.

FAO. (1992). Production Yearbook 1991. FAO, Rome.

Foster, J., Greer, J. \& Thorbecke, E. (1984). A class of decomposable poverty measures. Econometrica, 52, 761-6.

Fox, G. C. (1987). Resource allocation in public agricultural research: a survey. Journal of Agricultural Economics, UK, 38(3), 449-62.

Gittinger, J. P. (1982). Economic Analysis of Agricultural Projects. 2nd edition. Johns Hopkins University Press, Baltimore, MD.

Govt of India (1985). General population tables. Census of India 1981. Registrar General and Census Commissioner, India. New Delhi.

Govt of India (1990). Bulletin on food statistics, 1987-89. Directorate of Economics and Statistics, Dept of Agric. and Cooperation, Ministry of Agriculture, New Delhi.

Govt of India (1992). Area and production of principal crops in India, 1989-90. Directorate of Economics and Statistics, Dept of Agric. and Cooperation, Ministry of Agriculture, New Delhi.

Gryseels, G., de Wit, C. T., McCalla, A., Monyo, J., Kassam, A., Craswell, E. \& Collinson, M. (1992). Setting agricultural research priorities for the CGIAR. Agricultural Systems, 40, 59-103. 
ICRISAT (1991). Pathways to progress in the semi-arid tropics: ICRISAT's strategic plan for the nineties. Patancheru, A.P. 502 324, India: ICRISAT.

ICRISAT (1992a). ICRISAT's comments on the TAC paper entitled 'A review of CGIAR priorities - Part I: Advanced working draft'. (Internal document: Limited Distribution) ICRISAT.

ICRISAT (1992b). Medium Term Plan 1994-98: Volume I (Main Report). Board approved draft for submission to TAC/CGIAR. 28 September 1992.

Just, R. E., Hueth, D. L. \& Schmitz, A. (1982). Applied Welfare Economics and Public Policy. Prentice-Hall, Inc., New Jersey.

Kelley, T. G. (1992). An economist's contribution to an IARC's plans and strategies. Paper presented at the Meeting of the CGIAR Social Scientists, 17-20 August 1992, ISNAR, The Hague.

Lindner, B. (1987). Toward a framework for evaluating agricultural economics research. Australian Journal of Agricultural Economic, 31(2), 95-111.

Lynam, J. K. \& Herdt, R. (1988). Sense and sustainability: sustainability as an objective in international agricultural research. Paper for CIP-Rockefeller Foundation Conference on Farmers and Food Systems in Lima, Peru.

McCalla, A. F. \& Ryan, J. G (1992). Setting agricultural research priorities: lessons from the CGIAR study. American Journal of Agricultural Economics, (December) 1095-100.

Minhas, B. S., Jain, L. R. \& Tendulkar, S. D. (1991). Declining incidence of poverty in the $1980 \mathrm{~s}$. Evidence versus artifacts. Economic and Political Weekly, 26, 22-8.

Mueller, R. A. E. (1990). Choosing the right research pond: Figuring research priorities with implementation in mind. Resource Management Program, Economic Group Progress Report 103. ICRISAT. Patancheru, A. P. India. November 1990.

Norton, G. W. \& Davis, J. S. (1981). Evaluating returns to agricultural research: a review. American Journal of Agricultural Economics, (November) 685-99.

Norton, G. W. \& Ortiz, J. (1992). Reaping the returns to research. J. Prod. Agric., 5, 203-9.

Rohrbach, D. D. (1993). ICRISAT experience in research planning and prioritization. Paper prepared for the Workshop on Formulation of Faculty of Agriculture Research Programme up to the Year 2000, March 1993, Sokoine University of Agriculture, Morogoro, Tanzania.

Ruttan, V. W. (1982). Agricultural Research Policy. University of Minnesota Press, Minneapolies.

Ryan, J. G. \& Davis, J. (1988). Economic growth, technological change and priority assessment in agricultural research. ACIAR/ISNAR Project Paper No. 13, August.

Sen, A. (1979). Issues in the measurement of poverty. Scandinavian Journal of Economics, 81(2), 285-307.

Shumway, R. C. (1980). Models and methods used to allocate resources in agricultural research: a critical review. In Resource Allocation and Productivity in National and International Agricultural Research, eds T. M. Arndt, D. G. Dalrymple \& V. W. Ruttan. University of Minnesota Press, Minneapolis.

TAC Secretariat (1992). A review of CGIAR priorities and strategies (Advanced Working Draft - Rev. I). FAO, United Nations, Rome, March 1992. 
Traxler, G. \& Byerlee, D. (1992). Crop management research and extension: The products and their impact on productivity. CIMMYT Economics Paper No. 5 Mexico, D.F.

United Nations Development Program (1992). Human Development Report 1992.

UNESCO (1985). Statistical yearbook 1985. United Nations Educational Scientific and Cultural Organization, Paris.

von Oppen, M., Virmani, S. M. \& Parthasarathy Rao, P. (1985). Identification of priority areas for research on resource management at ICRISAT. Second draft, 4 November 1985. Internal ICRISAT document.

Vu, M. T. (1984). World Population Projections. The World Bank, Washington DC.

World Bank (1989). Gender and poverty in India: issues and opportunities concerning women in the Indian economy. Vol 1. September, 1989. World Bank Report No. 8072-IN. Washington DC.

World Bank (1990). World Development Report 1990: Poverty. Oxford University Press.

World Bank (1992). World Development Report 1992: Development and the Environment. Oxford University Press.

\section{APPENDIX - THEME DESCRIPTORS FOR MTP RESEARCH THEMES}

1. Constraint/Problem: Identifier of the theme or constraint addressed. Themes can be constraint-based (drawn directly from the yield loss estimates exercise), or topic-oriented, e.g. improving grain quality, conducting marketing/policy research.

2. Crop $(s)$ involved: Identifies the major crops concerned/affected.

3. Research domain: Identifies the primary and secondary research domains covered. Primary domains differ from secondary domains with respect to research lags (primaries are shorter), probabilities of success (primaries are higher), and ceiling levels of adoption. The concept of a secondary research domain is comparable to the notion of interregional 'spillovers'.

4. Type of research: According to the relative emphasis in the type of research proposed: strategic/basic, applied, or adaptive. Strategic/ basic research is concerned with the development of new knowledge and new technological components; not finished products like cultivars. Examples include gene mapping, methodology development, etc. Applied research represents the process of developing and testing a particular technology, e.g. screening advanced lines for pest resistance and quality traits. Adaptive research represents the final stage of testing of technologies nearing release in multilocation trials and on 
farmers' fields. All types of research were assessed in terms of expected final impacts, with the main differences in lead and lag times.

5. Research output: Lists the expected research products with probable time frames, i.e. milestones. Outputs are not limited to development of new technologies; other possibilities are new screening techniques, new methodologies and policy prescriptions. An attempt should be made to value and quantify all outputs. As a practical matter, only the outputs most directly related to the development of the new technology that increases or sustains crop yields in farmers' fields can be valued. In this exercise, only final research outputs (from ICRISAT's research perspective) were valued and quantified in terms of a delivery timetable. Intermediate research products (e.g. screening techniques, information) and milestones were also described but not valued similarly - due to the inherent difficulty of the task. Intermediate research outputs were taken into account implicitly when research themes were screened initially with respect to ICRISAT's comparative advantage.

6. Research and extension lags: Calculates the number of years required to reach each milestone, decomposed into discrete periods as follows:

$a=$ The number of years required by the institute to complete the proposed research aiming to develop a technology or technology component;

$b=$ the number of years required for NARS collaboration to incorporate the technology into a releasable form destined for farmers' fields;

$c=$ the number of years to the point of maximum adoption allowing achievement of the prospective yield gain.

Thus, $a+b+c$ is equivalent to the research and extension lag from the point of research initiation to the point of maximum farmer adoption (see Fig. 4). Estimation of $a, b$, and $c$ requires heroic assumptions in some cases. Scientists or experts will draw on their specific knowledge about the research and adoption process in a given region in predicting these time frames, e.g. $c$ might be especially long because of an undeveloped seed industry.

7. Adoption ceiling: Calculates the maximum level of adoption of the new technology achieved in year $\mathrm{O}+a+b+c$. Various adoption functions can be used to determine specific levels of adoption for the period between $b$ and $c$.

8. Probability of success: Estimates the likelihood of the research leading to the dissemination of a new technology or technology component for each research output and, where applicable, for primary and secondary 
domains are needed. There are other factors besides researchers' competence which can affect the probability of success, e.g. results being inconclusive. [See Bantilan and Davis (1991b) on factors affecting probability of research success.]

9. Senior scientist years: Calculates the number of internationally and nationally recruited scientists required per year by discipline over the full period of the research planned to achieve the defined output, disaggregated by annual input as necessary.

10. Yield improvement expected: This is the yield gain expected in farmers' fields which is attributed to the research effort proposed, ultimately translating into reductions in per unit production costs. [See Traxler and Byerlee (1992) on problems associated with attribution.]

11. Production costs: The incremental field production costs associated with the improved technology emanating from the proposed research.

12. Stability component: A proxy for the extent to which the proposed research theme will reduce yield variability from year to year or minimize the frequency or intensity of an epidemic-type stress.

13. Environmental/Sustainability contribution: This captures the extent to which the research is expected to generate - directly or indirectly - environmentally friendly outputs and positive (or negative) externalities.

14. Extra capital requirements: Calculates special capital needs to execute the research (e.g. growth chambers, electron microscope, malting equipment). 